\title{
Topographic Reorganization in the Striate Cortex of the Adult Cat and Monkey Is Cortically Mediated
}

\author{
C. Darian-Smith and C. D. Gilbert \\ The Rockefeller University, New York, New York 10021-6399
}

In primary sensory and motor cortex of adult animals, alteration of input from the periphery leads to changes in cortical topography. These changes can be attributed to processes that are Intrinsic to the cortex, or can be Inherited from alterations occurring at stages of sensory processing that are antecedent to the primary sensory cortical areas. In the visual system, focal binocular retinal lesions initially silence an area of cortex that represents the region of retina destroyed, but over a period of months this area recovers visually driven activity. The retinotopic map in the recovered area is altered, shifting its representation to the portion of retina immediately surrounding the lesion. This effectively shrinks the representation of the lesioned area of retina, and expands the representation of the lesion surround. To determine the loci along the visual pathway at which the reorganization takes place, we compared the course of topographic alterations in the primary visual cortex and dorsal lateral geniculate nucleus (LGN) of cats and monkeys. At a time when the cortical reorganization is complete, the silent area of LGN persists, indicating that changes in cortical topography are due to alterations that are intrinsic to the cortex. To explore the participation of thalamocortical afferents in the reorganization, we injected a series of retrogradely transported fluorescent tracers into reorganized and surrounding cortex of each animal. Our results show that the thalamocortical arbors do not extend beyond their normal lateral territory and that this physical dimension is insufficient to account for the reorganization. We suggest that the long-range intrinsic horizontal connections are a likely source of visual input into the reorganized cortical area.

[Key words: cortical topography, adult plasticity, visual cortex, topographic reorganization, lateral geniculate nucleus, retinal lesions]

Sustained removal of normal input to a focal region of adult sensory neocortex can dramatically alter the topographic organization of the target region over ensuing weeks. While this has been demonstrated for numerous species and cortical areas, including somatosensory (Rasmusson, 1982, 1988; Merzenich et al., 1983a,b, 1984; Rasmusson et al., 1986; Calford and Twee-

\footnotetext{
Received Apr. 25, 1994; revised Aug. 1, 1994; accepted Aug. 22, 1994

We thank Ella Leers for technical assistance and Peter Peirce for photography. This work was supported by a grant from the NSF (BNS-8918951) and a McKnight Development Award, and by a C. J. Martin Fellowship from the National Health and Medical Research Council of Australia.

Correspondence should be addressed to C. D. Gilbert, The Rockefeller Iniversity, 1230 York Avenue, New York, NY 10021-6399.

Copyright $(1995$ Society for Neuroscience $0270-6474 / 95 / 151631-17 \$ 05.00 / 0$
}

dale, 1988, 1991), motor (Sanes et al., 1988, 1990, 1992; Donoghue et al., 1990), auditory (Robertson and Irvine, 1989; Rajan et al., 1993), and visual systems (Gilbert et al., 1990; Kaas et al., 1990; Chino et al., 1991, 1992; Heinen and Skavenski, 1991; Gilbert and Wiesel, 1992), the connections responsible for this reorganization have been a subject of debatc. To definc the mechanisms of cortical reorganization, it is necessary to ascertain where along the sensory pathway the changes take place, and to determine the anatomical substrate(s) for these changes. In the present study, visual input was removed from a defined region of striate cortex of adult cats and monkeys by focal, homologous binocular retinal lesions. While thalamic connections and the spread of thalamocortical arbors within the cortex have been proposed as a possible neural substrate for cortical reorganization (Merzenich et al., 1983a; Calford and Tweedale, 1988; Rajan et al., 1993; see Snow and Wilson, 1991 for review), evidence for their actual contribution in the adult animal is limited (Rasmusson and Nance, 1986; Wells and Tripp, 1987; Garraghty and Kaas, 1991), and differs across systems and species. For example, after ligating the ulnar and median nerves in the somatosensory system of the squirrel monkey, Garraghty and Kaas (1991) observed a topographic reorganization of the ventrobasal complex which corresponded to cortical changes. But in the raccoon, digit amputation resulted in cortical changes which were not mediated subcortically through brainstem nuclei or thalamocortical afferents (Rasmusson and Nance, 1986; Rasmusson, 1988). In the visual pathway, Eysel and colleagues have shown limited recovery of function within the cat dorsal lateral geniculate nucleus (LGN) after making small bilateral retinal lesions (Eysel et al., 1980, 1981), but this was restricted to a $200 \mu \mathrm{m}$ range, and corresponding cortical changes were not explored.

Substantial cortical reorganization has now been reported in somatosensory cortex (Pons et al., 1991) and in visually deprived cortex in monkeys following bilateral lesions (Gilbert et al., 1990; Heinen and Skavenski, 1991; Gilbert and Wiesel, 1992) and cats where focal lesions in one eye were accompanied by enucleation or occlusion of the second eye (Chino et al., 1992; Kaas et al., 1990; Schmid et al., 1993). Invariably, the most substantial reactivation of cortical cells takes weeks to occur, and neurons in the deprived cortex come to represent fields from retina surrounding the lesions. Though the extensive alteration of cortical topography progresses over a period of months, some changes immediately follow the retinal lesions, including large expansions in receptive field (RF) size and small shifts in RF position (Gilbert and Wiesel, 1992). Short-term changes are documented further in the present study.

Here we have used bilateral retinal lesions in the cat and mon- 


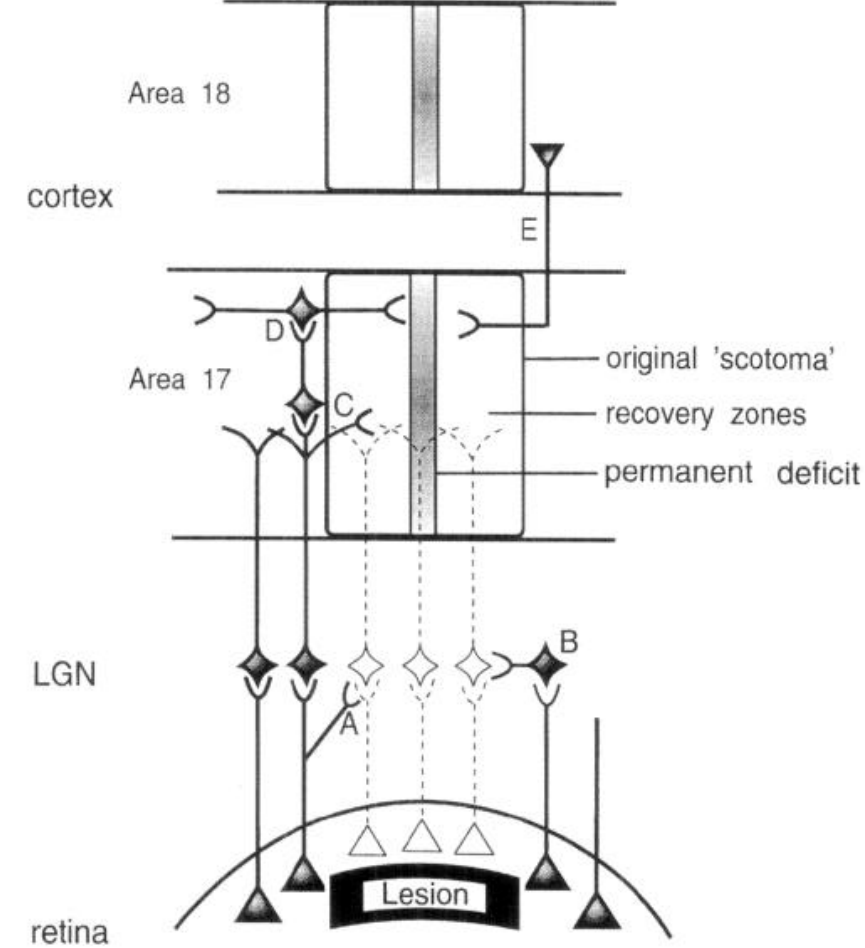

Figure 1. Summary diagram of possible steps at which changes may occur along the visual pathway. Alterations in the cortical topographic map could, in theory, originate at the level of the retina, via the extension (or sprouting) of retinogeniculate projections $(A)$, within the LGN as a result of lateral connections within that nucleus $(B)$, in the cortex as a result of the spread (or sprouting) of thalamocortical arbors $(C)$, through long-range horizontal connections formed by cortical pyramidal cells $(D)$, or feedback connections from other cortical areas, such as area $18(E)$.

key to examine the extent of long-term cortical reorganization and to correlate this directly with subcortical and thalamocortical contributions within the visual pathway, using both physiological and anatomical approaches. When lesions were made in a matching region of each eye, visually driven activity could not be elicited from neurons within a corresponding $5-10 \mathrm{~mm}$ diameter region of cortex. Two to 12 months later, this visually unresponsive area of visual cortex, or "cortical scotoma," again became responsive, this time to stimulation of the perilesion retina. (Though the term "scotoma" refers to a lesioned region of retina, we have extended the term to cover the silenced area of cortex and LGN resulting from a retinal lesion.) Figure 1 summarizes schematically the potential pathways through which information could be conveyed from intact retina to visually deprived cortex. Any changes occurring within the retina or LGN should be reflected in the topography of the LGN; if the changes are cortical in origin the part of the LGN representing the lesioned area of retina should be permanently silenced. We focused further downstream at intrinsic thalamic connections and geniculocortical afferents as possible sources of the reorganization.

A preliminary report of some of the findings reported here was published previously (Gilbert and Wiesel, 1992).

\section{Materials and Methods}

Seven cats (13 hemispheres, and over 21 recording sessions) and four macaque monkeys (seven hemispheres and over 17 recording sessions) were used in this study. Cats were obtained as adults and monkeys were older than 2.5 years of age, with initial body weights ranging between 4.0 and $6.0 \mathrm{~kg}$. Table 1 lists identification numbers, postlesion survival times, and other information specific to each animal.

Surgery. Following initial induction of anesthesia with ketamine hydrochloride ( $10 \mathrm{mg} / \mathrm{kg}$ body weight), a venous cannula was inserted and the animal intubated with an endotracheal tube. Anesthesia was maintained using $\mathrm{Na}$ thiopental $(1-3 \mathrm{mg} / \mathrm{kg} / \mathrm{hr})$, and monitored using EEG. Mannitol was administered ( $8-10 \mathrm{cc}$; intravenous) to lower intracranial pressure. Animals were paralyzed using intravenous infusion of either succinylcholine chloride $(10 \mathrm{mg} / \mathrm{kg} / \mathrm{hr})$ in cats, or Norcuron (vecuronium bromide; $0.8-1.2 \mathrm{mg} / \mathrm{kg} / \mathrm{hr}$ ) in monkeys. All animals were artificially respired. Surgery was conducted under aseptic conditions and EEG, EKG, expired $\mathrm{CO}_{2}$, and rectal temperature monitored continuously. A craniotomy was made over the visual cortex and the dura reflected. After dilating the pupils, and refracting the retinae, contact lenses were chosen to focus the eyes onto a tangent screen positioned in front of the stereotaxic apparatus. Once physiological recording or injection of dyes was complete, paralytic agents were discontinued and anesthesia maintained for the remainder of the surgery, until animals could breathe unaided by the respirator. Artificial dura (Tecoflex. Thermedics Inc., Woburn, MA) was inserted within subdural space, the dura mater sutured, the bone flap replaced, and the scalp wound closed. Antibiotics were administered pre- and post-operatively.

All retinal landmarks, including the position of the area centralis/fovea, and the boundaries of retinal lesions were projected onto the tangent screen using a fundus camera (Zeiss).

Mapping cortical receptive fields. Insulated tungsten microelectrodes were used to obtain single and small multiunit recordings in both cats and monkeys. Receptive fields were mapped, using a hand-held stimulator, from cells within a series of penetrations made perpendicular to the cortical surface and restricted to the superficial layers (no deeper than $450 \mu \mathrm{m}$ ). In cats, recording sites were aligned rostrocaudally along the dorsal surface of area 17, and parallel to the midline. In monkeys, receptive fields were mapped initially from cells within $30-40$ vertical penetrations made within an approximate $1.5 \mathrm{~cm}^{2}$ cortical exposure (see Fig. 5). Receptive fields (RFs) were mapped according to "minimum response" characteristics, and properties such as orientation selectivity, ocular dominance, and directionality noted. Unusual or apparent altered response properties were documented after retinal lesions had been made.

Each electrode penetration was marked on photographs of the brain surface taken just prior to each recording session. Surface vasculature as well as dural scarring in the cat were used as fiducial marks when returning to recording sites during the same and in subsequent experiments.

Mapping LGN receptive fields. Receptive field maps of the LGN were always obtained during the final acute experiment. In the cat (Figs. 2, 3), the LGN was located stereotaxically (Sanderson, 1971, for the cat: Malpeli and Baker, 1975, for monkey). Once located. RFs were mapped every $300 \mu \mathrm{m}$ through the extent of each penetration (see Figs. $2 B, 3 B$, and $7 A, B$ ) and a number of penetrations were made at $500 \mu \mathrm{m}$ intervals along anteroposterior and mediolateral axes. Two to four small electrolytic lesions were made $(4 \mu \mathrm{A} \times 8 \mathrm{sec})$ where penetrations passed through or along the border of unresponsive tissue. These lesions were later identified histologically and aligned with retrogradely labeled populations of geniculocortical neurons terminating at injection sites placed along the boundary of the original cortical scotoma. The depth of recording sites and ocular dominance characteristics were documented to determine laminar progression, and for later analysis and reconstruction.

Retinal lesions. Retinal lesions were made as described previously (Gilbert et al., 1990; Gilbert and Wiesel, 1992). Once the initial cortical $\mathrm{RF}$ map was completed, the electrode was returned to a location within the cortex corresponding to the center of the desired site of the lesion. Using audio output from the electrode, we were able to stimulate cortical neurons using a guide light from the ophthalmic laser (Iris Instruments) focused onto the corresponding region of retina. Visually driven activity from cortical neurons was thus used to guide the placement of the lesions. Once retinal lesions were made in the appropriate locus, cortical cells were immediately silenced or unresponsive to visual stimulation. Typically in the cat, the diode laser required a strength of 800 $\mathrm{mW}$ and $800 \mu \mathrm{sec}$ duration to destroy the pigment epithelium and photoreceptor layer. In the monkey we used $1000 \mathrm{~mW}$ for a period of 800 $1000 \mu \mathrm{sec}$. Postmortem histology was used to check for damage to the ganglion cell layer. Retinal vasculature remained intact and was visible within the lesion during subsequent experiments. 
Table 1. Details of each of the experimental animals used in the present investigation

\begin{tabular}{|c|c|c|c|c|c|}
\hline ID & $\begin{array}{l}\text { Postlesion } \\
\text { (wks) }\end{array}$ & $\begin{array}{l}\text { LGN } \\
\mathrm{RF} \\
\text { maps }\end{array}$ & $\begin{array}{l}\text { Lesions } \\
\left({ }^{\circ} \operatorname{arc}\right)\end{array}$ & $\begin{array}{l}\text { Cortical scotoma size } \\
\text { at time zero }(\mathrm{mm})\end{array}$ & $\begin{array}{l}\text { Widths of cortical } \\
\text { reorganization }(\mathrm{mm})\end{array}$ \\
\hline \multicolumn{6}{|l|}{ Cats } \\
\hline cat \#1R & 19 & $\checkmark$ & $\begin{array}{l}\mathrm{R}=3.5^{\circ} \times 4^{\circ} \\
\mathrm{L}=4.5^{\circ} \times 5^{\circ}\end{array}$ & $R=4.4 ; L=3.3$ & ○ \\
\hline cat \#1L & & $\sqrt{ }$ & & $\mathrm{R}=6.5 ; \mathrm{L}=4.4$ & 0 \\
\hline cat $\# 2 \mathrm{R}$ & 15 & $\sqrt{ }$ & $\begin{array}{l}\mathrm{R}=7^{\circ} \times 11^{\circ} \\
\mathrm{L}=6^{\circ} \times 10^{\circ}\end{array}$ & $\mathrm{R}=3.9 ; \mathrm{L}=3.6$ & - \\
\hline cat \#2L & & $\sqrt{ }$ & & $\mathrm{R}=4.5 ; \mathrm{L}=4.0$ & - \\
\hline cat \#3R & 15 & $\sqrt{ }$ & $\begin{array}{l}\mathbf{R}=8^{\circ} \times 12.5^{\circ} \\
\mathbf{L}=8^{\circ} \times 14.5^{\circ}\end{array}$ & $\mathrm{R} \approx 5.0$ & $2.5,2.1$ \\
\hline cat \#3L & & $\sqrt{ }$ & & $\mathrm{R}=4.6 ; \mathrm{L}=4.6$ & 0 \\
\hline cat \#4R & 12 & $\sqrt{ }$ & $\begin{array}{l}\mathrm{R}=11^{\circ} \times 16.5^{\circ} \\
\mathrm{L}=12^{\circ} \times 16^{\circ}\end{array}$ & $\mathrm{R}=11.0 ; \mathrm{L}=9.5$ & $2.5,2.5$ \\
\hline cat \#4L & & $\sqrt{ }$ & & $\mathrm{R}=9.0 ; \mathrm{L}=7.0$ & $2.5,2.5$ \\
\hline cat $\# 5 \mathrm{R}$ & 10 & $\checkmark$ & $\begin{array}{l}\mathrm{R}=8.5^{\circ} \times 17.5^{\circ} \\
\mathrm{L}=8.5^{\circ} \times 16^{\circ}\end{array}$ & $\begin{array}{l}\mathrm{R}=6.7 ; \mathrm{L}=7.0 \\
\text { (overlap }=5.5 \text { ) }\end{array}$ & $\begin{array}{l}\mathrm{O}=3.7,2.5 ; \mathrm{R}=3.5,1.9 \\
\text { overlap } \mathrm{L}=2.5 ; \mathrm{R}=2\end{array}$ \\
\hline cat $\# 5 \mathrm{~L}$ & & $\sqrt{ }$ & & $\begin{array}{l}\mathrm{R}=7.2 ; \mathrm{L}=7.3 \\
\text { (overlap }=5 \text { ) }\end{array}$ & $\begin{array}{l}O \mathrm{R}=2.3,2.0 ; \mathrm{L}=3.2,1.5 \\
\text { overlap } \mathrm{L}, \mathrm{R}=1.9\end{array}$ \\
\hline cat \#6R & & & N/A & N/A & \\
\hline cat $\# 6 \mathrm{~L}$ & & & N/A & N/A & \\
\hline cat \#7L & 45 & $\checkmark$ & $\begin{array}{l}R=14^{\circ} \times 19^{\circ} \\
L=13^{\circ} \times 20^{\circ}\end{array}$ & $\mathrm{R}=7.0 ; \mathrm{L}=7.0$ & 2.5, 2.0 \\
\hline \multicolumn{6}{|l|}{ Monkeys } \\
\hline $\mathrm{m} \# 1 \mathrm{R}$ & 10 & $\sqrt{ }$ & $\mathrm{R}=3^{\circ}, \mathrm{L}=3^{\circ}$ & & $3.0,-$ \\
\hline $\mathrm{m} \# 2 \mathrm{R}$ & 52 & $\checkmark$ & $\mathrm{R}=4^{\circ}, \mathrm{L}=4^{\circ}$ & $8 \times 5.8$ & $2.6,1.5$ \\
\hline $\mathrm{m} \# 2 \mathrm{~L}$ & & $\checkmark$ & $\mathrm{R}=4^{\circ}, \mathrm{L}=5^{\circ}$ & $9.5 \times 5$ & 3.0,1.5 \\
\hline $\mathrm{m} \# 3 \mathrm{R}$ & 26 & $\checkmark$ & $\mathbf{K}=6^{\circ}, \mathrm{L}=5.5^{\circ}$ & $12 \times 9.5$ (overlap) & $05.0,3.0$ \\
\hline $\begin{array}{l}m \# 3 L \\
m \# 4 R \\
m \# 4 L\end{array}$ & & $\checkmark$ & $\begin{array}{l}\mathrm{R}-6^{\circ}, \mathrm{L}-6^{\circ} \\
\text { N/A } \\
\text { N/A }\end{array}$ & $\begin{array}{l}5 \times 9 \text { (overlap) } \\
\text { N/A } \\
\text { N/A }\end{array}$ & O $5.0,3.0$ \\
\hline
\end{tabular}

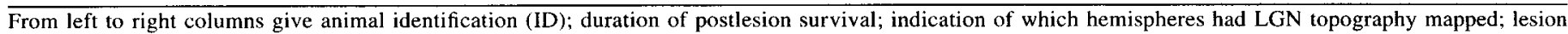

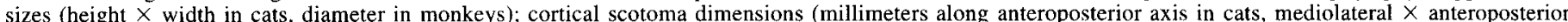

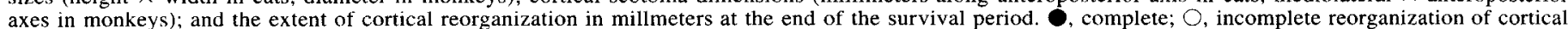

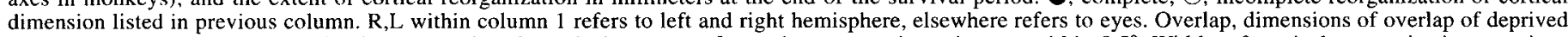

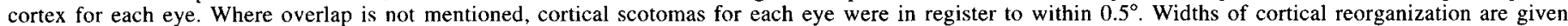
as maximum and minimum distances fron the original boundary of the contical scotona, measured at postlesion survival periods indicated in column 1.

Fluorescent dye injections. Single injections $(0.3-0.35 \mu \mathrm{l})$ of each of 3-4 fluorescent dyes [Fast blue $(\mathbf{F})$, Diamidino yellow (D), Rhodamine beads $(\mathrm{R})$, and Green beads $(\mathrm{G})]$ were made into the striate cortex 2 weeks before the final experiment. Approximately $0.3-0.4 \mu \mathrm{I}$ of each dye was pressure injected at a depth of $600-800 \mu \mathrm{m}$ through glass micropipettes ( $1.2 \mathrm{~mm}$ o.d.; tip diameter $30-60 \mu \mathrm{m}$ ). All injection sites were reconstructed by mapping the putative uptake zones (see Keizer et al., 1983; Darian-Smith and Darian-Smith, 1993) in every third or fourth sequential tangential section $(150-160 \mu \mathrm{m}$ intervals; see mapping system next section). Table 2 lists the maximum diameter of each injection and minimum separation between neighboring sites. Injections involving the underlying white matter were discarded. For details of the dye solutions and perfusates used, see Darian-Smith et al. (1990a).

Retrogradely labeled neurons within the $d L G N$. The criteria used to identify single- and double-labeled neurons within the lateral geniculate nucleus has been described in some detail previously (Darian-Smith et al., 1990a). Serial coronal (monkeys) or parasagittal (cats) sections were cut (at $40 \mu \mathrm{m}-50 \mu \mathrm{m}$ thick) through the lateral geniculate nucleus. Every section or alternate section (80-100 $\mu \mathrm{m}$ intervals) was mapped for labeled neurons within the LGN using a computer-linked digitizing system (Datametrics MDPlot Inc.) attached to a fluorescence microscope. Alternate sections were stained or counterstained with cresyl violet to determine the distribution of labeled neurons within each layer of the LGN, and to localize sites of electrolytic lesions.

Three-dimensional analysis of data within the LGN of monkeys. De- spite sections being cut coronally, multiple populations of labeled cells were not easily compared through sequential sections of one monkey or across animals. Consequently, the distribution patterns of 3-4 distinct populations of labeled neurons within the LGN were reconstructed in three-dimensional space (VersaCad), which allowed the data to be manipulated and viewed in any plane (see Fig. 8). This was not necessary in the cat, where important information could be gleaned from twodimensional maps of sections cut in a parasagittal plane.

\section{Results}

Visuotopic organization of the striate cortex

A detailed baseline map of RFs was obtained for each eye and both hemispheres in all animals prior to making retinal lesions. In the cat this included 14 pairs of maps from seven animals; two examples are shown in Figures $2 A$ and $3 A$. Recordings were made from a strip of 1116 vertical penetrations positioned rostrocaudally and located close to the midline. The use of the dorsal surface of the striate cortex, rather than the medial bank of the superior lateral gyrus, enabled us to return to the same recording sites at later time intervals, using cortical vasculature for reference. As expected, the majority of cells were binocular and almost exclusively characterized as complex (Hubel and 
Figure 2. A, RF maps for cat \#4 prelesion, immediately after lesioning, and several months later; and $B$, RFs for LGN of the same animal, 3 months postlesion. Insets in A show the dorsal view of the lateral gyrus of the cat's visual cortex, with the circles representing electrode penetrations (recording sites) in visually responsive cortex (open circles) and unresponsive cortex (filled circles). These indicate that the silent region had shrunk from $7.5 \mathrm{~mm}$ along the anteroposterior axis immediately postlesion to $2 \mathrm{~mm} 3$ months later. The gray rectangles represent $\mathrm{RF}$ sizes, orientations, and positions at each recording site. At each stage of recovery recordings were made at the same or similar sites, using cortical vasculature and dural landmarks as fiduciary references. In the 3 month recovery recordings, RFs mapped at many cortical sites had shifted from positions within the zone of the scotoma to positions immediately outside it, as indicated by the arrows. Scale marker $=1^{\circ} . B$, Recording sites in LGN (left), made after cortical reorganization, are superimposed on a dorsal view reconstruction of the LGN. The HorseleyClarke coordinates are shown. Open circles mark penetrations in visually responsive sites, and filled circles indicate penetrations along which significant stretches of visually unresponsive LGN were observed. The diameter of the visually unresponsive area was $1-$ $1.5 \mathrm{~mm}$, which approximates the normal representation of the lesioned retina. RFs mapped along these penetrations indicated a normal progression within the visual field, with no "bunching up" of RFs near the boundary of the lesion, and no significant change in the size of the RFs. For penetrations where RF positions could be mapped either side of the scotoma, visually unresponsive zones were encountered which extended for $1-1.5 \mathrm{~mm}$. Scale marker $=1^{\circ}$.

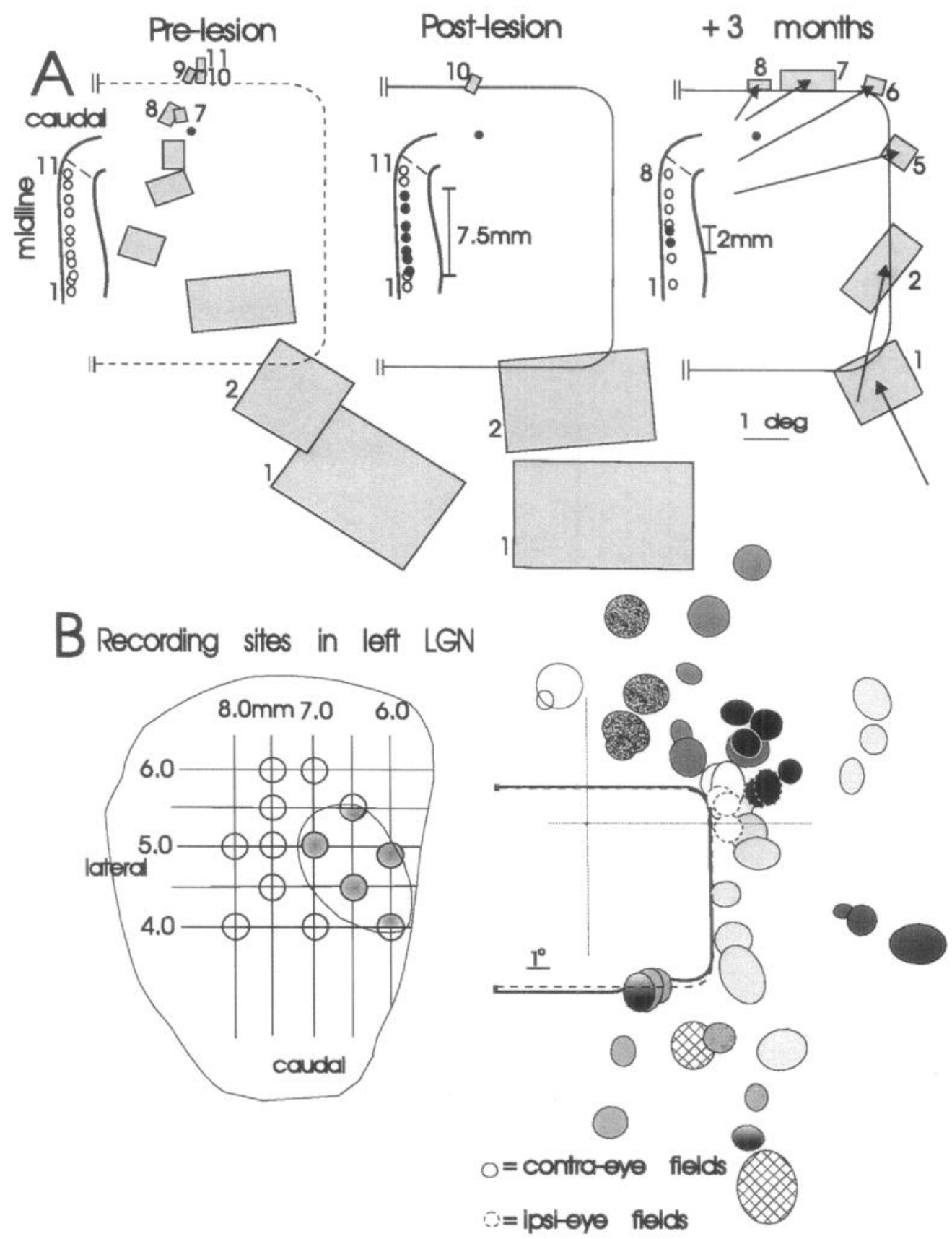

Wiesel, 1962). Moving the recording electrode from rostral to caudal positions within the cortex gave a progression of RFs from eccentricities of $-15^{\circ}--20^{\circ}$ toward the area centralis (Fig. $2 A$, left). Retinal lesions were always located within the inferior visual quadrant and within $2^{\circ}$ of the area centralis. While RF maps were always topographic, we frequently noted individual distortions in field representation (Tusa et al., 1978). This was particularly apparent when comparing the rostrocaudal extent of cortex involved in two cats after lesions of comparable size and location were made in both. For example (see Table 1), an $8.5^{\circ}$ retinal lesion in cat \#5 involved 6.7-7.3 mm of cortex, while an $8^{\circ}$ lesion in cat \#3 mapped onto less than $5 \mathrm{~mm}$ of cortex.

In monkeys, RFs were mapped from a series of 30-40 recording sites made in each of seven hemispheres (four monkeys), and within an approximate $1.2 \times 1.2 \mathrm{~cm}$ area of the opercular surface of the striate cortex (see Figs. 5 and 6; Hubel and Wiesel, 1974). RF maps were made for both eyes, and covered eccentricities of $0^{\circ}-7^{\circ}$ from the fovea and within inferior visual quadrants.

\section{Immediate effects of retinal lesions}

We observed consistent changes in RF properties immediately (between $5 \mathrm{~min}$ and up to $1 \mathrm{hr}$ ) after making matching retinal lesions of $3.5^{\circ}-14^{\circ}$ diameter (see Table 1) in both eyes. Some of these results have been described previously (Gilbert and Wiesel, 1992). Immediately after lesions were made, visually driven responses could not be elicited from cortical sites originally located more than $0.5-1.0 \mathrm{~mm}$ inside the lesion boundary. In Figures $2 A$ and $3 A, 7.0$ and $7.5 \mathrm{~mm}$ of cortex, respectively, was silenced. For cortical sites located close to or just inside the cortical scotoma boundary, however, cells showed a striking increase in RF size. The size of these RFs fell outside the normal 


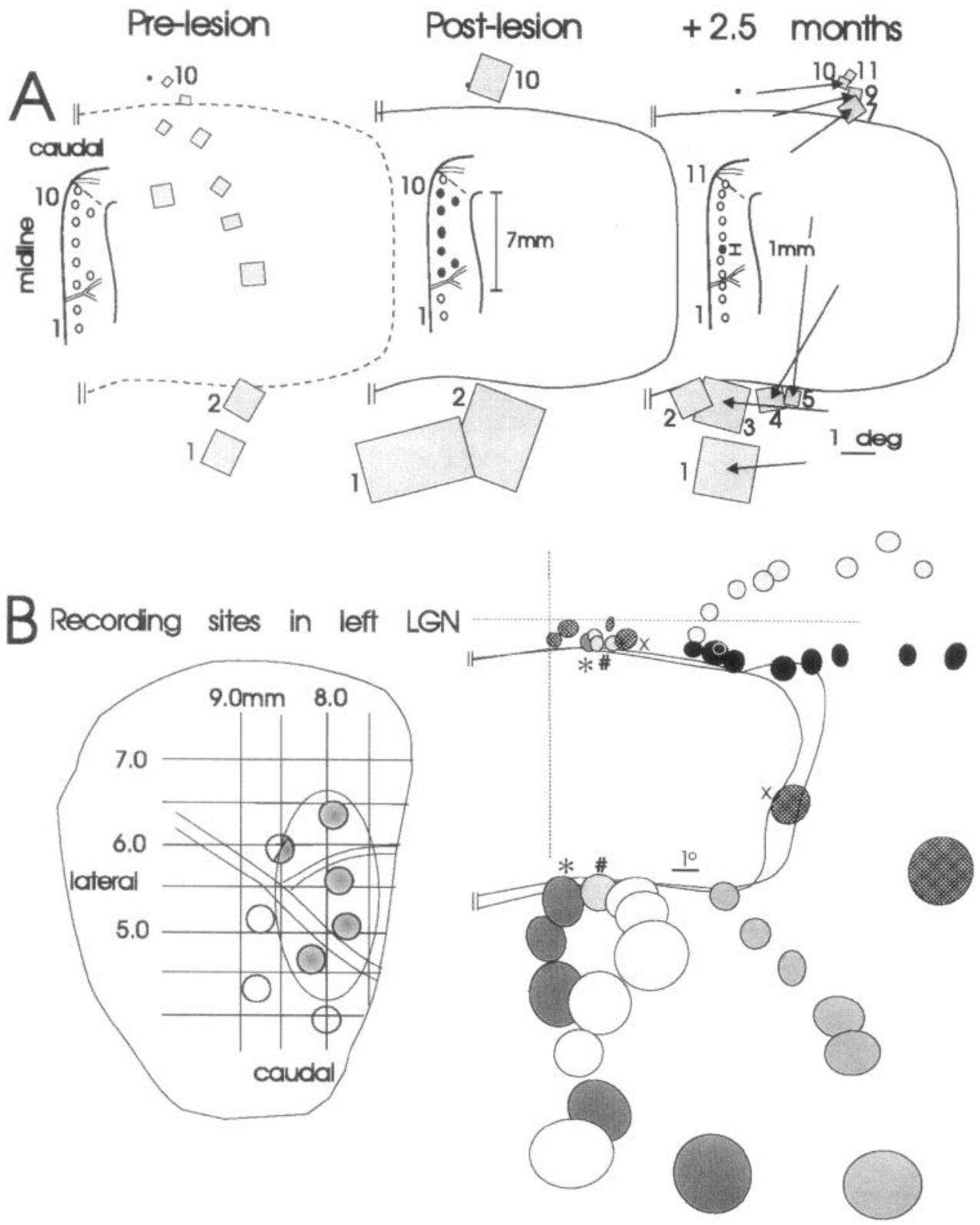

Figure 3. A second example (cat \#5) of cortical reorganization following binocular retinal lesions $(A)$, with a corresponding map of the LGN $(B)$ made 2.5 months after lesioning. Symbols are the same as for Figure 2 . Whereas cortical reorganization was documented over $6 \mathrm{~mm}$ of cortex, the LGN retained a large silent area which extended for $1-2.5 \mathrm{~mm}$ in diameter. This indicated a lack of appreciable reorganization occurring within the LGN. RFs mapped along single penetrations and extending through the scotoma are identified by shading type. Projections which passed through the silent region, and where RFs could be mapped either side of the scotoma, are marked by a star, an asterisk, and a cross. The depth of unresponsive LGN along these trajectories was measured between 1.4 $1.6 \mathrm{~mm}$.

range for neurons at these depths and eccentricities (Hubel and Wiesel, 1974; Gilbert and Wiesel, 1992). For example, in cat \#5 (Fig. 3A) RF expansion was as much as 10-fold (sites 1, 2, and 10), while in cat \#4 (Fig. $2 A$ ) this increase was less prominent, about twofold. The change in receptive field size at increasing distances from the boundary of the cortical scotoma is plotted in Figure 4. Data was pooled from seven cats and 14 hemispheres (one cat and two hemispheres were included from a separate study), and RF pairs (pre- and postlesion) were mapped from the same recording sites (within $100 \mu \mathrm{m}$ of the previous site), and within the superficial layers. Results shown in Figure 4 show that the greatest changes occur for cells with RFs located closest to the scotoma boundary. In addition, RFs were shifted a short distance in visual space to lie outside the lesion. While it could be argued that individual RF shifts are small and may result from small eye movements, their consistent centrifugal displacement from the lesion center indicates that they are directly related to the effect of the lesion.

Cells in the recovered area of the cortical scotoma were less responsive than those in normal cortex or cortex located more than $1 \mathrm{~mm}$ outside the boundary of deprived cortex. These cells were distinctly delayed or sluggish in their initial response and typically fatigued after multiple stimulus sweeps. Even so, these cells retained certain characteristics observed in normal cortex, such as directionality, orientation specificity, and binocularity.

\section{Long-term reorganization of cortex}

Maps made within the same cortex 2-12 months after creating retinal lesions showed a dramatic topographic reorganization. Cortical neurons located several millimeters inside the original boundary of the deprived cortex were once again responsive, this time to stimulation of perilesion retina. Details of the extent of cortical reorganization are given in Table 1 and typical examples illustrated within the inserts of Figures $2 A$ and $3 A$. Several features of reorganization were common to all animals: First, function returned to the cortex in a roughly concentric inward direction. This was particularly obvious in the monkey 
Table 2. Injections of fluorescent retrograde tracers in normal and reorganized cortex of cats and monkeys, tabulating the label injected $(\mathrm{D}$, diamidino yellow; $\mathrm{F}$, fast blue; $\mathrm{G}$, green beads; $\mathrm{R}$, rhodamine beads), their relative positions (A-G), diameter (numbers within the lettered columns), and distances between injections (numbers between lettered columns)

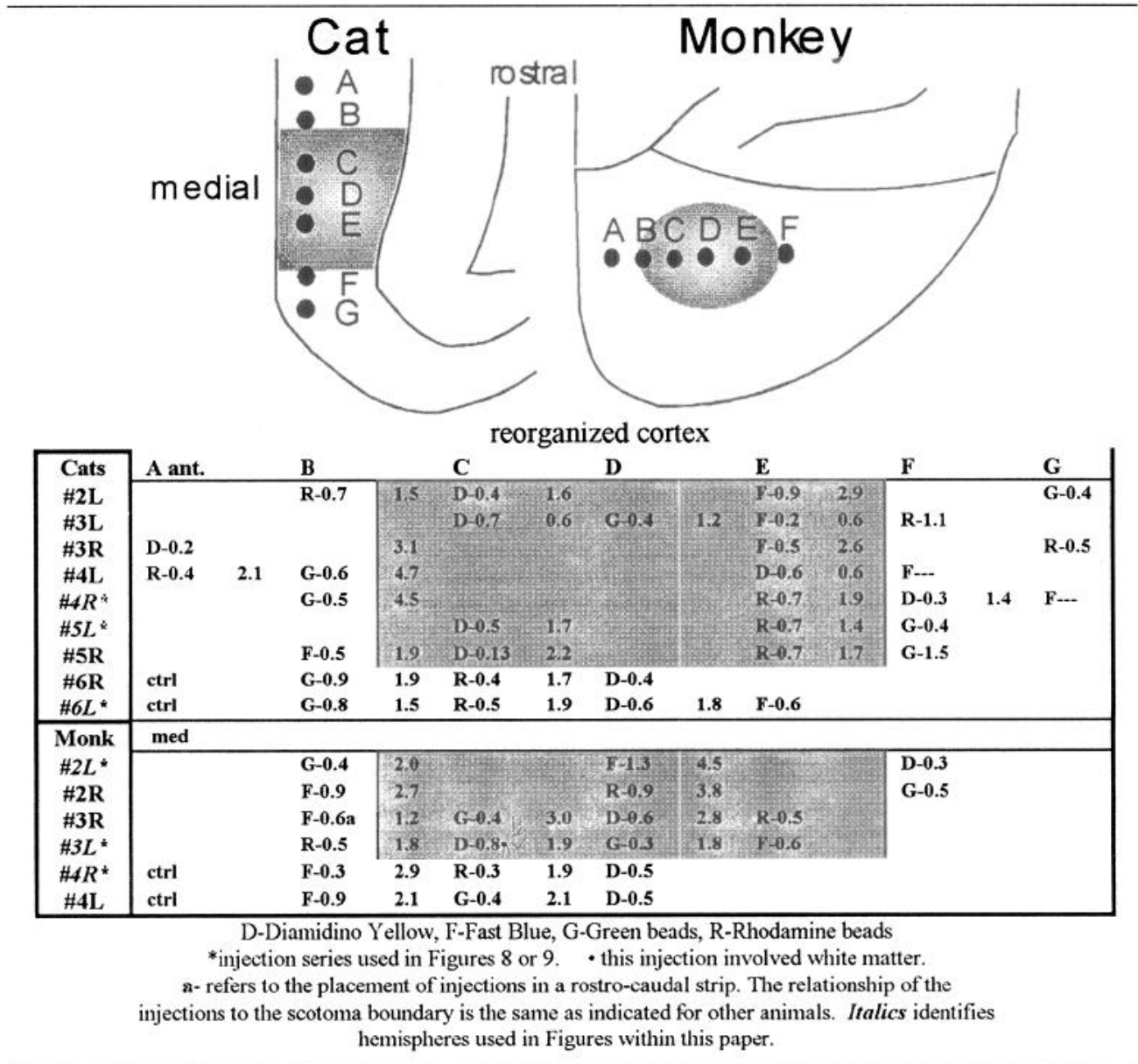

Distances are conservative estimates of the minimum separations between the outer boundaries of the injection sites. See Materials and Methods for injection site definitions.

(Figs. $5 A, B ; 6 A, B$ ), where it was possible to record activity from a larger dorsal exposure of cortex.

The cortical reorganization can be expressed either in terms of the area of cortex recovering visually driven activity and undergoing reorganization, or, for cells at a given cortical site, in terms of the extent of visual field over which one observes shifts in their RF positions. The extent of cortical reorganization is quantified in one of two ways: as either the total fill-in of activity within a cortical scotoma or the fill-in from a given edge of the scotoma boundary ("one-sided" fill-in), which would be expected to be roughly half of the total fill-in. For example, thalamic arbors extending for $2 \mathrm{~mm}$ could provide approximately $1 \mathrm{~mm}$ of fill-in from each edge of the scotoma, assuming there is a more or less symmetrical distribution of the axonal tree around the main trunk. Alternatively, it can refer to a total fillin of $2 \mathrm{~mm}$ of cortex, or $1 \mathrm{~mm}$ from each side. Unless stated, we describe reorganization as fill-in from a given edge of the scotoma boundary.

In the cat we typically observed reorganization for a lateral distance of $2.5-3.0 \mathrm{~mm}$ of cortex from the original boundary ("one-sided") of deprived cortex. This is apparent in cat \#4 (Fig. $2 A$, inserts), where $5.5 \mathrm{~mm}$ of what was originally a $7.5 \mathrm{~mm}$ silent region recovered function (total fill-in), and in cat \#5 (Fig. $3 A$ ), where there was a total fill-in of $6 \mathrm{~mm}$. In the monkey this lateral distance of recovery was typically greater, with visually responsive cortex as much as $4.5-5.0 \mathrm{~mm}$ inside the initial boundary ("one-sided") of the cortical scotoma. There was no correlation between the extent of reorganization and the postlesion survival for periods of longer than 2.5 months, suggesting an approximate tangential limit for recovery progressing from the boundary of the lesion toward its center (Gilbert et al., 1990). In the present study the longer survival periods of 11 (cat \#7, two hemispheres) and 12 months (monkey \#2, two hemispheres) did not lead to an extension of reorganization beyond a $5 \mathrm{~mm}$ limit.

Cortical reorganization was also defined in terms of RF shifts in visual space. At an eccentricity of $5^{\circ}$, RFs mapped for the same cortical sites before and months after the lesions shifted as much as $5^{\circ}$ (Figs. $2 A, 3 A$ in the cat; Fig. 5 for the monkey; shifts are indicated by arrows and measured using RF centers) to lie outside the scotoma border. In effect, they receive input from a part of the visual field several hypercolumn widths away. Importantly, topographic order was maintained in all animals even if there were distortions in representation. This is apparent 


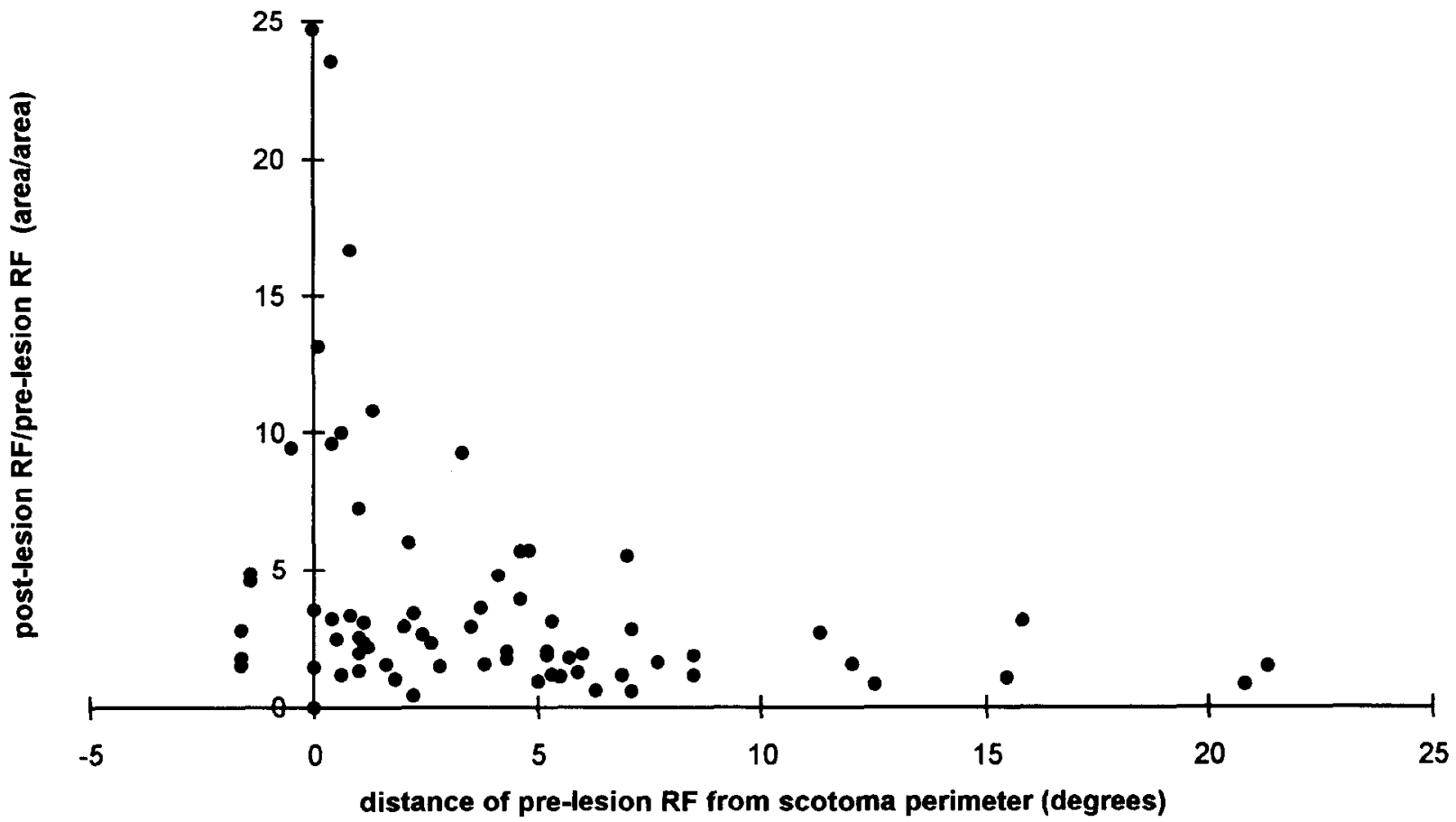

Figure 4. Short-term changes in RF size seen in the striate cortex of seven cats (14 hemispheres) immediately after retinal lesions were made. Abscissa indicates distance of RF center from the boundary of the retinal lesion (degrees), and ordinate indicates the ratio of RF area measured immediately postlesion/RF area measured at the same cortical site before lesioning. The greatest changes were observed for RFs initially located closest to the boundary of the scotoma.

in Figures $3 A$ (cat) and $6, A$ and $B$ (monkey), where RFs have moved as much as $4-5^{\circ}$. When a silent region of cortex remained after months to a year of recovery, this region was always located central to the original cortical scotoma (see Figs. 2, 3, 5, 6 ). RFs in the perilesion fields were frequently (see Figs. $3 A$, $6 A, B$ ) but not always larger (see Fig. $2 A$ ) than observed at equivalent eccentricities in the original RF map.

\section{$R F$ maps within $L G N$}

RF maps were produced for 10 LGNs in the cat and five LGNs in the monkey up to 1 year after creating retinal lesions (see Table 1). In all animals, extensive topographic reorganization had already been documented within the cortex (see above and Table 1). Thalamic RF maps illustrated for the cat in Figures $2 B$ and $3 B$ correspond to the cortical maps shown from the same animals (Figs. $2 A, 3 A$, respectively). In the monkey, RF maps for LGN (Fig. 7) were made in the same hemispheres from which the cortical maps illustrated in Figure $5 B$ were taken. RFs were mapped at regular $300 \mu \mathrm{m}$ intervals along vertical penetrations (see dorsal view of LGN at left of figures) through the full depth of the LGN. The electrode penetrations were angled oblique to the isoazimuth and isoelevation lines in the LGN, so that successive recordings encountered cells with RFs in different visuotopic locations as well as at different depths and layers. As a consequence we frequently passed through responsive and unresponsive regions within the same penetration. In all animals, the passage of electrodes through the central medial portion of the LGN in the cat revealed a large visually unresponsive zone (approximately $1-1.5 \mathrm{~mm}$ in the dorsoventral dimension). For electrode tracks passing directly through the silent region, it was possible to find sharp boundaries between populations of cells with visual responses and visually unresponsive cells, and then to measure the corresponding dimensions of the silent thalamic zone. At the transition between silent and visually responsive zones we made electrolytic lesions and compared their location with distributions of retrogradely labeled cells (see below and Figs. 8, 9). Trajectories for RFs mapped along each electrode track and emerging either side of the scotoma can be followed in Figures $2 B$ and $3 B$ (RFs with like fill). Similarly, in the monkey illustrated in Figure 6A, arrows marking RFs mapped either side of the scotoma were separated by $1.8 \mathrm{~mm}$. This visually unresponsive region of LGN contrasted dramatically with what was frequently complete reorganization within the cortex. The progression in receptive field position was continuous, with no "bunching up" or abnormal overlay of receptive fields near the boundary of the lesion, as seen in the cortical maps. Though we cannot rule out small changes (in the order of $200 \mu \mathrm{m}$ ) occurring along the boundary of the deprived LGN, as has been previously reported in the cat (Eysel et al., 1980, 1981), the size of the silent region approximated the normal representation of the lesioned portion of retina. For example, in the monkey a distance of $1.5 \mathrm{~mm}$ on the surface of the LGN represents $4^{\circ}$ of visual angle at $4^{\circ}$ eccentricity (Malpeli and Baker, 1975; Fig. 7), while in the cat $1.5 \mathrm{~mm}$ equates to the representation of visual space between $1^{\circ}$ and $10^{\circ}$ eccentricity (Sanderson, 1971).

\section{Anatomical investigations into geniculostriate projections}

The absence of appreciable physiological reorganization within the LGN indicated that the mechanism involved is intrinsic to the cortex. Figure 1 illustrates schematically the theoretical steps along the visual pathway where changes could be occurring. It was unlikely that any reorganization was being mediated within the retina since damage from the lesion was permanent and the integrity of the ganglion cell layer did not alter observations made further along the pathway. If reorganization within the LGN was occurring via retinogeniculate afferents this would 

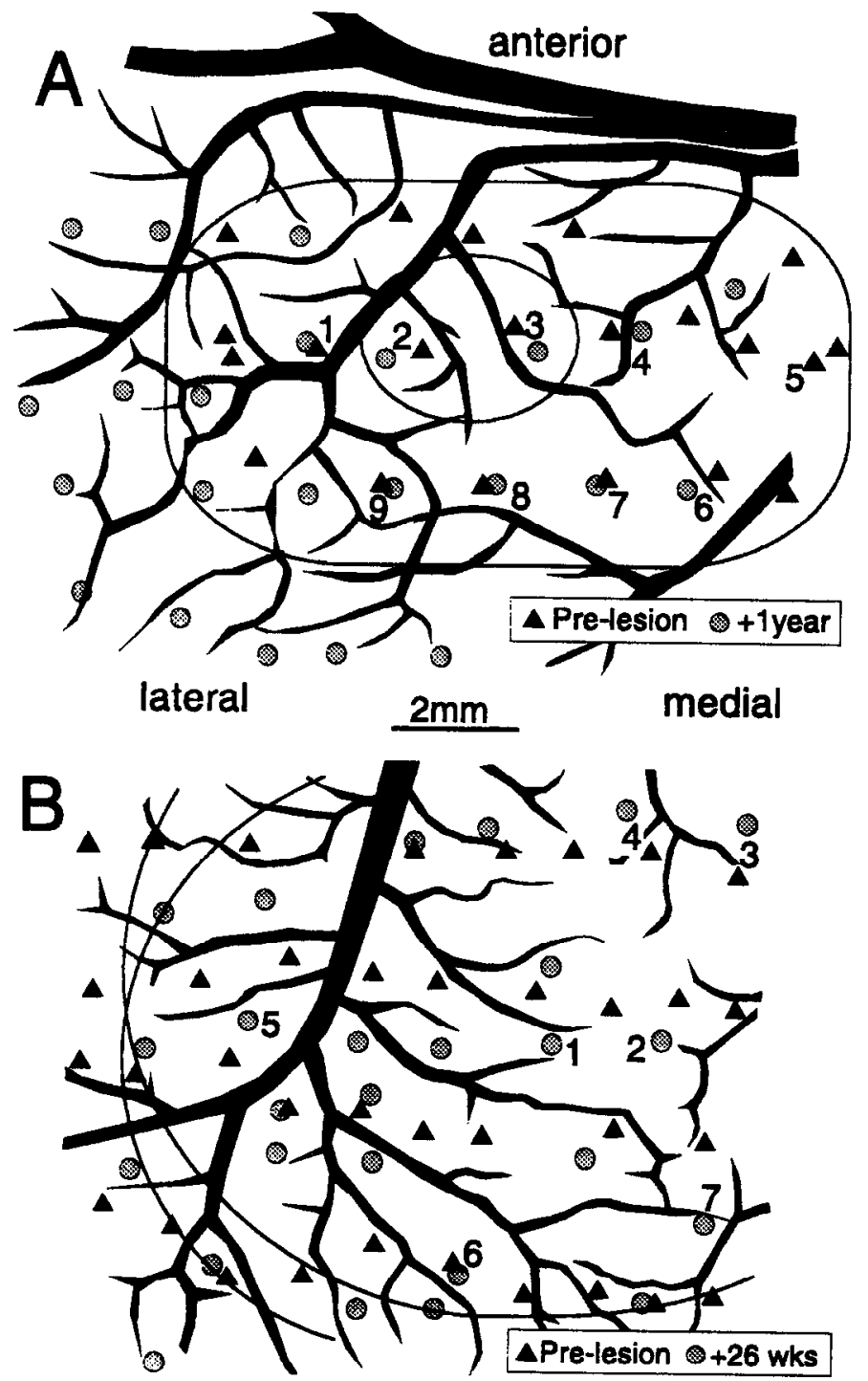

Figure 5. Recording sites for cortical RF maps made in monkey striate cortex (corresponding RF maps are shown in Fig. 6). Dorsal view of striate cortex (operculum) shown with vascular pattern and positions of recording sites before making retinal lesion (triangles) and $A, 1$ year later and $B, 26$ weeks later (shaded circles). In $A$ the outer ring indicates the area of cortex initially inactivated by the lesion, and the inner ring defines the remaining core of silent cortex following reorganization. In $B$ the two rings delineate the representation of the initially inactivated region for each eye. Scale marker $=2 \mathrm{~mm}$.

have to occur through terminal sprouting since the normal spread of these fibers is too narrow (Mason and Robson, 1979). By recording from the $\mathrm{LGN}$ we were able to preclude a significant contribution from any of these steps, and conclude that the first candidate for connections that might be responsible for transmitting visual information from normal to reorganized cortex is the population of thalamocortical afferents.

We employed an anatomical approach to explore this possibility, labeling populations of cells in the LGN projecting to different sites across the regions of normal and reorganized cortex. Since the lateral spread of afferents within normal striate cortex (Ferster and LeVay, 1978; Gilbert and Wiesel, 1979, 1983; Blasdel and Lund, 1983; Humphrey et al., 1985; Freund et al., 1985, 1989) rarely exceeds $2 \mathrm{~mm}$, with approximately 1 $\mathrm{mm}$ of this extending from the unaffected afferents immediately outside the boundary of the cortical scotoma into the scotoma, afferent collaterals would need to sprout latcrally (Fig. $1 B, C$ ) beyond their normal extent to account for the cortical reorganization observed in this study $(2.5-3.0 \mathrm{~mm}$ in cats and up to 5 $\mathrm{mm}$ in monkeys). Up to four different retrogradely transported fluorescent dyes were injected into selected cortical sites in each of five cats (seven lesioned hemispheres, two control) and three monkeys (four lesioned hemispheres, two control). Injections were placed in normal cortex, immediately outside the boundary of the original cortical scotoma and within the topographically reorganized zone. Table 2 shows the placement of injection sites relative to these positions, the maximum diameter of each, and minimum distances separating neighboring sites. The 52 injections used in our analysis were localized within the cortex and had a mean diameter of $0.6 \mathrm{~mm}$. For specific characteristics of the injection sites of each dye see Darian-Smith et al. (1990a). Both the necrotic zone and surrounding zone of intense label were used in the reconstruction of the Fast blue and Diamidino yellow injections. The resulting distribution patterns of labeled neurons projecting from the LGN to the cortical injection sites are illustrated in Figures 8 (cats) and 9 (monkeys).

Electrolytic lesions were made during the final recording session to mark the physiological boundary of the visually unresponsive region within LGN, and these are shown in the maps of panels $A$ and $B$ in Figures 8 and 9. These were identified histologically (Fig. 10) and superimposed on the maps. Their positioning correlated well with distribution territories of cell populations projecting to injections along the original boundary of the cortical scotoma, and corroborates the dimensions of the silent region calculated during the RF mapping sessions (see above). Figure 8 includes three separate series of parasagittal maps of sections cut through the medial portion of the LGN in reorganized (Fig. $8 A, B$ ) and normal (Fig. $8 C$ ) cats. Figure 9 shows three series of coronal maps taken through the posterior pole of the LGN in reorganized (Fig. 9A,B) and normal (Fig. $9 C$ ) monkeys. The three-dimensional reconstructions illustrated in this figure enabled data to be synthesized from a much larger series of 30-40 maps and manipulated in three-dimensional space. Together these series illustrate the major findings and common features of organization described below:

A topologic organization was maintained for all projections to injection sites in both reorganized and normal cortex, as expected from topographic maps documented in LGN. This is clearly seen in Figures 8 and 9 as a series of bands or projection columns (Sanderson et al., 1971) spanning laminar layers through the depth of the LGN. In the cat, more caudal bands of cells projected to more posterior injection sites in the striate cortcx, whilc more rostral populations terminated in progressively more anterior injection sites. In the monkey, anteromedial projection columns terminated in laterally positioned injection sites, while more medial injection sites (closer to foveal representation) received input from more posterior and lateral projection columns. No distortion of this topological order was apparent in any of the animals used in this study.

The width of projection territories terminating in injection sites located both inside and just outside the original boundaries of the cortical scotoma were also examined. If an extension of afferent terminals within the cortex was responsible for sending perilesion information to the reorganized zone, then we would have expected to see a widening of projection territories within LGN, specifically for populations projecting to injections located 


\section{Receptive field shifts in the striate cortex}

\section{A}

Day \#1-pre retinal lesion

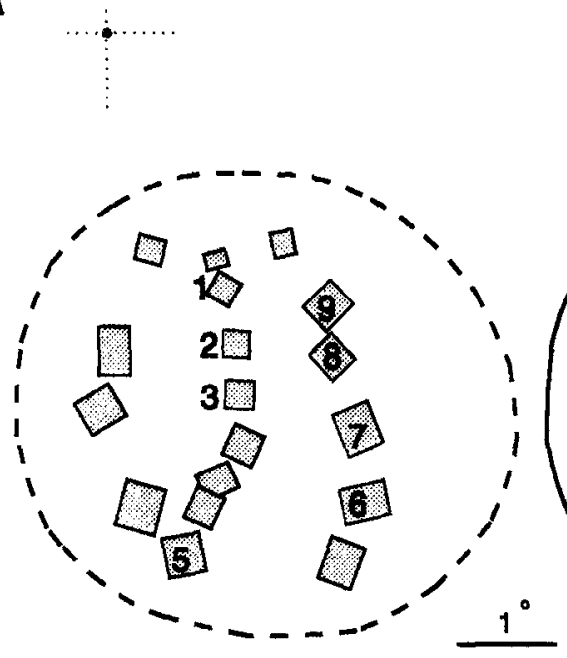

\section{+1 year}

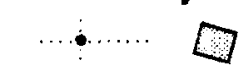

Q

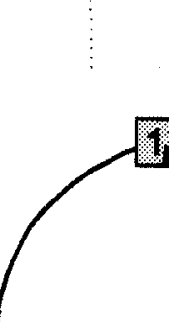<smiles>C1CCC2CCCC2C1</smiles>

\section{B}

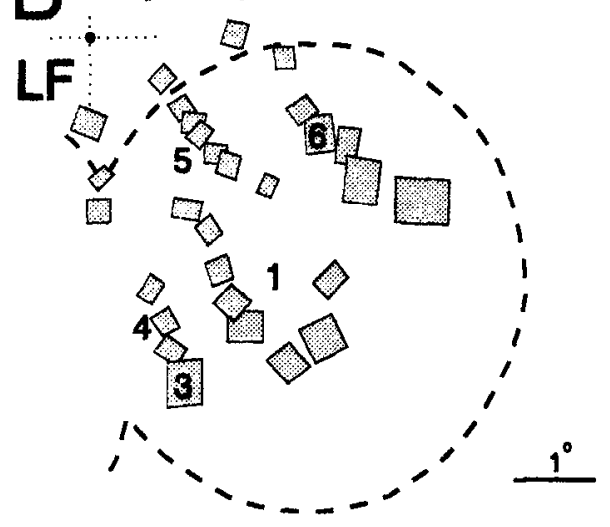

$$
+26 \text { weeks }
$$
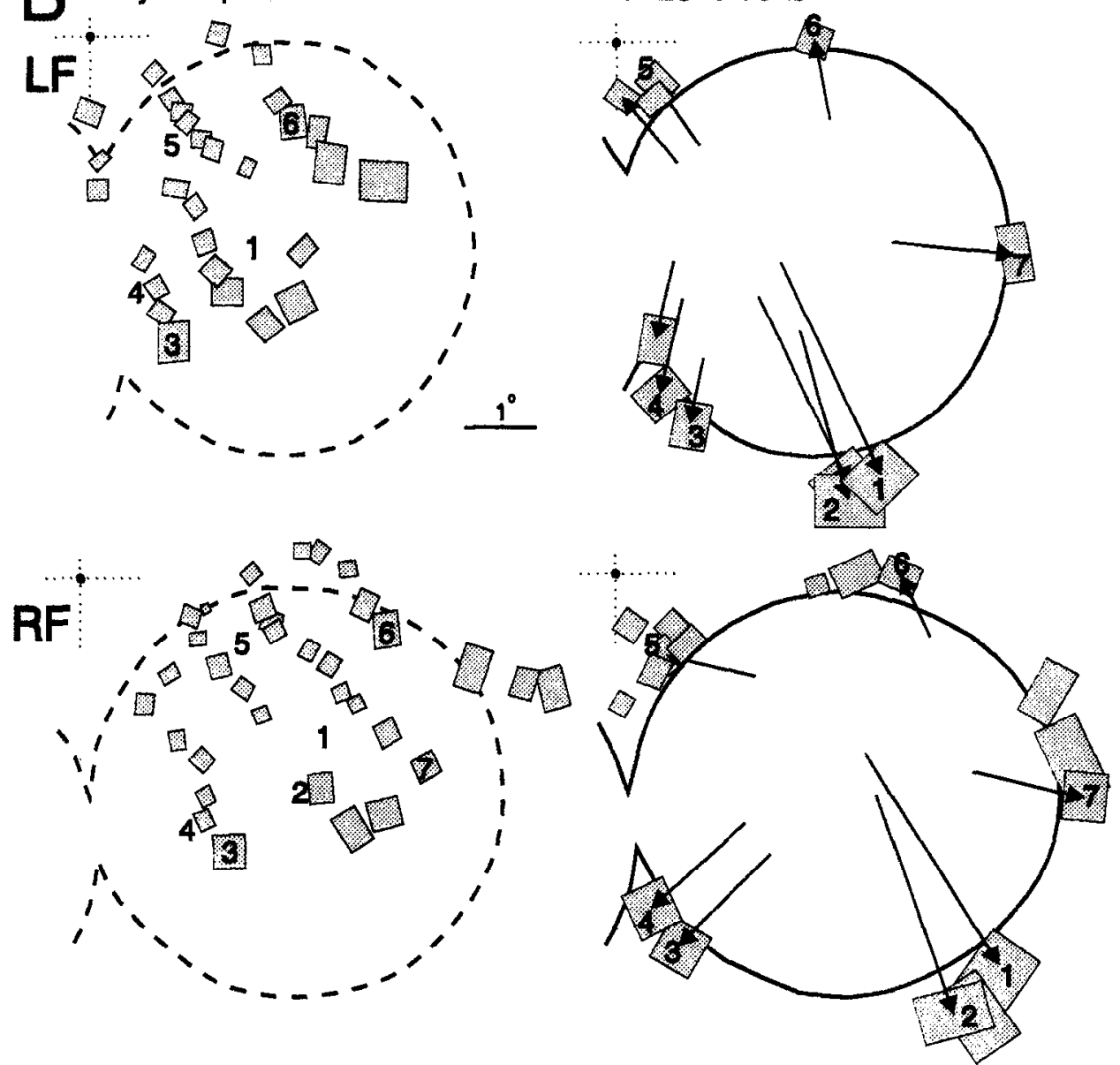

Figure 6. Receptive field maps for monkey \#2 (A, left hemisphere) and monkey $\# 3$ ( $B$, left and right eye for left hemisphere) made prior to lesioning and following long-term recovery. Numbered $R F$ s refer to recording sites in Figure 5. Arrows indicate shifts in $\mathrm{RF}$ positions for matched recording sites before lesioning and after 1 year $(A)$ and 26 weeks $(B)$ of recovery. The black spot intersected by dotted lines marks the position of the fovea. within reorganized cortex. Moreover, we would have expected dye injections inside the reorganized cortical area to label cells outside the boundary of the silent LGN, or on the active side of the LGN scotoma. But this was not the case. Figures 8 and 9 show the contrary, that any injection placed inside the cortical scotoma labels LGN cells within the unresponsive part of the LGN; and so the scotoma receives no direct input from visually responsive cells within the LGN. The widths of projection territories never exceeded the range observed in normal animals when comparisons were made between labeled populations ter- 
A

Recording sites for left LGN

5.0

$13.0 \mathrm{~mm}$

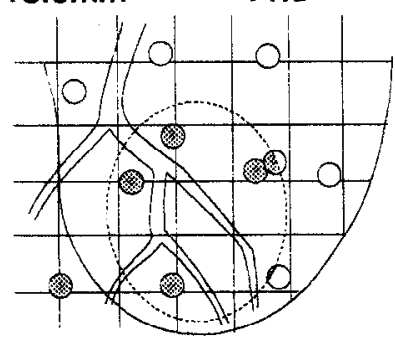

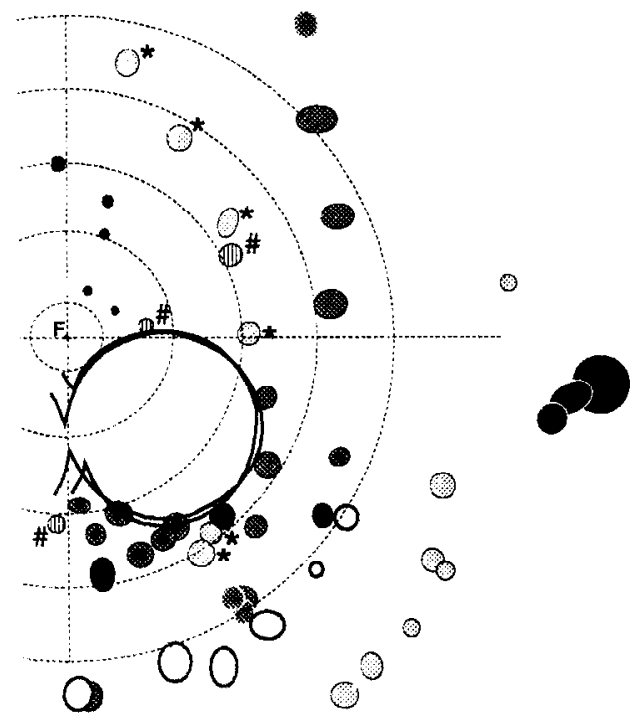

Figure 7. RF maps for LGN in the left $(A)$ and right $(B)$ hemispheres of monkey \#3. On the left are reconstructions of the dorsal view of LGN with vertical electrode penetrations in visually responsive (open circles) and unresponsive (shaded circles) sites. Horseley-Clarke coordinates and large vessels are indicated on the overlying cortex. On the right are RF maps made along these vertical penetrations (shading type indicates RFs found along a given penetration). The position of the fovea $(F)$ and visual axes are indicated (stippled lines), and the scotoma boundaries in the two eyes are represented by irregular circles.

Recording sites for right LGN
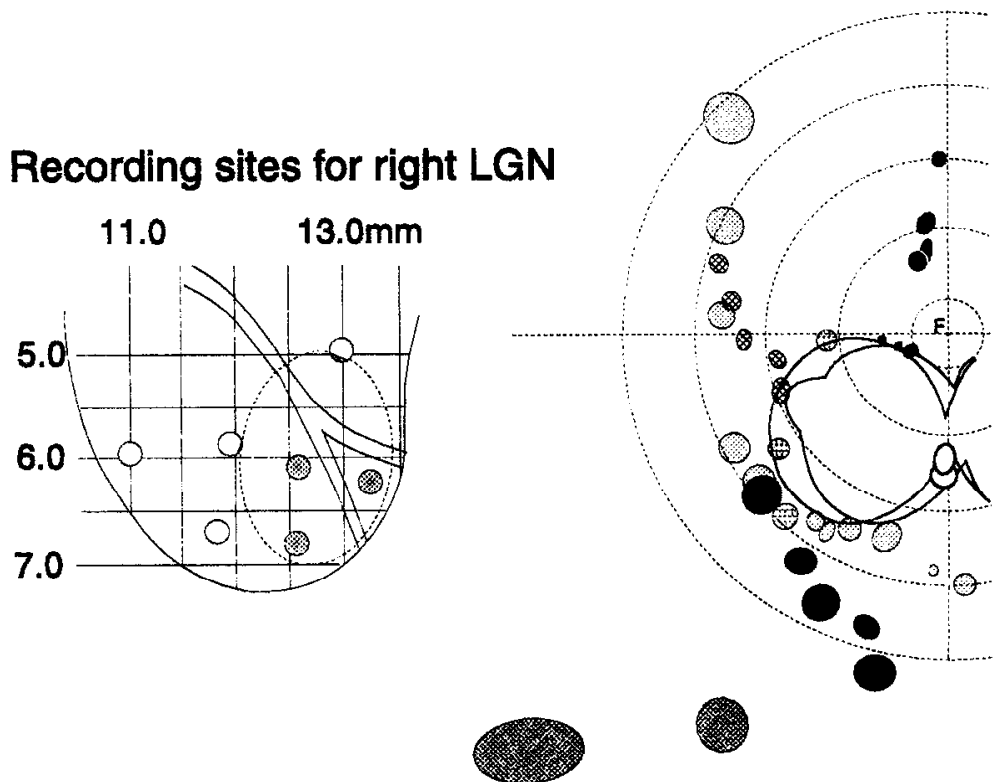

minating in injection sites at similar visuotopic locations. This is illustrated in Figure 8 when you compare the rostrocaudal width of the red population of cells in $A$ (target injection within reorganized cortex) with the yellow or red populations in $C$ (target injection within normal cortex). In addition, we did not observe an increase in the overlap of projection territories terminating in injection sites positioned outside and inside the boundary of the original cortical scotoma.

To provide additional support for the above observations, double-labeled (DL) neurons were also mapped systematically (11 cat and five monkey LGNs). The distance between target injection sites gives the lateral spread of afferent collaterals within the cortex, and DL neurons projecting to injections outside and more than $2.0 \mathrm{~mm}$ inside the reorganized cortex would infer an extension of afferent terminals beyond their normal territory. Very few DL neurons were encountered in the LGN of any of the animals used in this study. When they were observed they were invariably located within the normal spatial overlap of cell populations projecting to ncighboring injections within the cortex. When the minimum distance between injection sites was less than $1.8 \mathrm{~mm}$ we frequently observed 3-6 DL neurons per map (less than $6 \%$ of the smaller population of labeled neurons within LGN). When this distance exceeded $1.8 \mathrm{~mm}$ they were never observed. The same rule applied for both lesioned and normal hemispheres irrespective of the relative positioning of injections within the cortex.

For the monkey, where the relative distributions of the different labeled cell populations were more difficult to visualize in single sections than in the cat, we made three-dimensional reconstructions of the fields of labeled cells. When rotated to the appropriate view, it was possible to see the distinct separation between the populations labeled with the different retrograde tracers, and to compare the pattern of labeling between hemispheres with normal and reorganized cortex (Fig. 9B,C). 


\section{Discussion}

The present findings support the conclusion that the reorganization of cortical topography following retinal lesions originates in the cortex, and is likely to be mediated, at least in part, by the long-range collaterals of cortical cells rather than by thalamocortical afferents. Visual activity was shown to return to a $6-$ $10 \mathrm{~mm}$ diameter region of cortex (with the more extensive fillin in the monkey). Cells initially silenced by the lesions came to represent retina immediately surrounding the deprived zone, so that RFs overlapped along the buundary of the visual scotoma and there was an expansion in representation of periscotoma space. In contrast to the findings in the cortex, physiological mapping of the LGN revealed a large silent zone approximating the size of the normal representation of the lesioned retinal area. Anatomical evidence corroborated the physiological dimensions of the silent zone, and showed that reorganization did not occur to a significant degree within the LGN. This indicated that neither retinal reorganization nor the intrinsic circuitry of the LGN was responsible for relaying visual information from the perilesion retina to the reorganized cortical locus. In addition, distributions of cells projecting to 3-4 localized injection sites placed inside and outside the reorganized cortex were examined in each LGN to see whether afferent neurons extended into the deprived cortex over distances sufficient to account for the reorganization. The maintained segregation and narrow spread of populations of retrogradely labeled cells showed that neither the span of preexisting afferent terminals nor the extension of afferents beyond their normal territory could be responsible for mediating the 3-5 $\mathrm{mm}$ of reorganization observed. If cells immediately outside the boundary of the cortical scotoma and cells 1.5-5 mm within reorganized cortex (with cells at both sites having overlapping RFs) had received input from the same thalamic neurons, either directly or via collateral branching in layer 4 , this would have been reflected in a widening of the distribution territories of labeled cell populations within the LGN, with an obvious increase in the spatial overlap (and double labeling) of these neuron distributions. Moreover, injections made into the reorganized cortex would have retrogradely labeled distributions of cells outside the silent region of the LGN, and this clearly did not happen. This study has shown that, at least within the visual system, extensive topographic reorganization (beyond $1-1.5 \mathrm{~mm}$ ) is not mediated subcortically. Rather, input to the cortical scotoma is likely to be conveyed through cortical cells lying outside of it. A plexus of horizontal conncctions is one candidate for this projection (Gilbert and Wiesel, 1979, 1983, 1989; Rockland and Lund, 1982, 1983; Martin and Whitteridge, 1984). Unlike the LGN afferents, these connections are sufficiently widespread normally to propagate visual information over the required distances. We have suggested that while they may normally have a subthreshold modulatory influence, through sprouting of their long-range collaterals this influence may be increased to suprathreshold levels (Darian-Smith and Gilbert, 1994). The sprouting does not require an increase in the longest reach of these collaterals, but rather an enrichment of the clusters of collateral arbors within the envelope of the existing axonal field. Among widespread connections within the cortex, these collaterals represent the most likely source of reorganization, though we have not discounted the participation of feedback connections from other cortical areas. Though feedback corticocortical connections are also widespread, those from V2 do not appear to be as extensive as the horizontal connec- tions arising from cells in the same cortical area, though the lateral extent depends on which cortical area is the source of the feedback (Rockland and Virga, 1989; Rockland et al., 1994).

While recent work has demonstrated that the sensory neocortex of adult animals is capable of topographic reorganization, the circuitry responsible for the reorganization was not determined. The present study has attempted to pin down the neural basis of this phenomenon. Several features of our approach make this determination particularly accessible. The bilateral retinal lesions used were easily and sharply demarcated and typically overlapped in visual space to an accuracy of approximately $0.5-1^{\circ}$. This produced localized matching regions of inactivity (involving ocular dominance columns for both eyes) inside essentially normal cortex. While other groups working within the visual pathway have demonstrated extensive reorganization after removing the entire input from one eye and lesioning the other (Kaas et al., 1990; Chino et al., 1992), it is unclear how the removal of one of the sources of activation to surrounding cortex may influence functional recovery. Another salient aspect of the present study was that for each animal (both cats and monkeys), we were able to correlate anatomical data directly with functional maps of the cortex and LGN (Figs. 2-10). The fact that we were able to obtain results in both cats and monkeys, which differed only in detail and extent (larger in monkeys), implies that similar response mechanisms to retinal damage or peripheral sensory injury may be common to a broad spectrum of mammals.

The use of the multiple retrograde tracer technique in the present study allowed us to visualize the distribution of afferent neurons within the LGN with terminal arbors extending from normal into deprived cortical areas. The absence of cells with terminal arbors spreading over $1.8 \mathrm{~mm}$ fits with earlier descriptions of these afferents in normal cortex (Ferster and LeVay, 1978; Gilbert and Wiesel, 1979, 1983; Blasdel and Lund, 1983; Freund et al., 1985, 1989; Humphrey et al., 1985). Our conclusions are further supported by the fact that all doublelabeling combinations were easily visualized, with different combinations of dyes placed inside and outside the cortical scotoma producing similar distribution patterns and labeling within the LGN.

The neural substrates responsible for long-term reorganization are likely to depend in part on the cortical dimensions over which changes occur. Many of the studies of the last decade in the somatosensory and auditory systems (Rasmusson, 1982; Kelahan and Doetsch, 1984; Merzenich et al., 1983a,b, 1984; Robertson and Irvine, 1989; Allard et al., 1991; Turnbull and Rasmusson, 1991; Rajan et al., 1993) looked at changes limited to a 2-3 $\mathrm{mm}$ diameter region of cortex, which are well within the normal range of thalamocortical arbors, and therefore suggestive of their participation as the neural substrate. The more recent observations of more extensive cortical involvement in visual (Gilbert and Wiesel, 1990, 1992; Kaas et al., 1990; Heinen and Skavenski, 1991) and somatosensory systems (Rasmusson et al., 1985; Pons ct al., 1991; Ramachandran et al., 1992) raised the suspicion that thalamocortical afferents are insufficient to account for the reorganization.

The present work does not rule out a role for thalamocortical afferents in the process of cortical reorganization, but does restrict that role to the normal physical bounds of the available terminal arbors $(>1-1.5 \mathrm{~mm})$. It is also possible that thalamic afferents play an important role in the mechanisms of short-term changes described here and elsewhere (Calford and Tweedale, 


\section{A Cat\# 5-Projections to reorganized cortex}

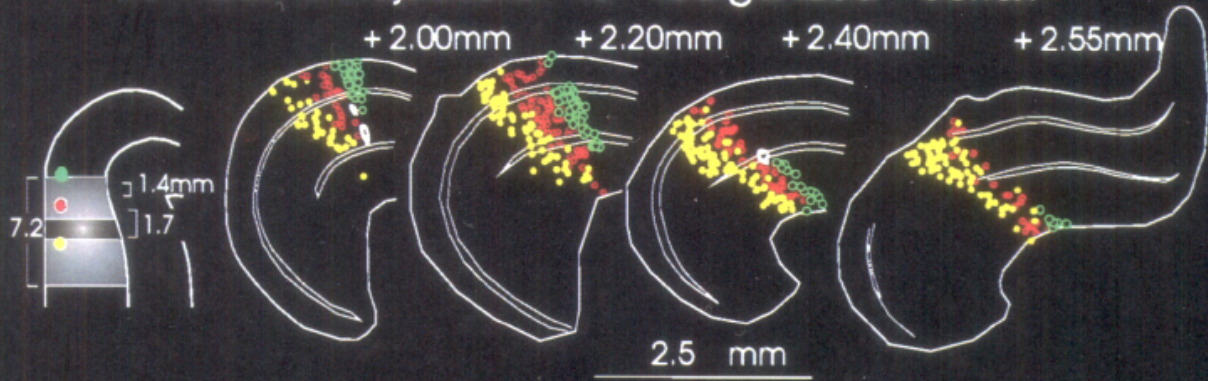

\section{B. Cał\# 4-Projections to reorganized cortex}
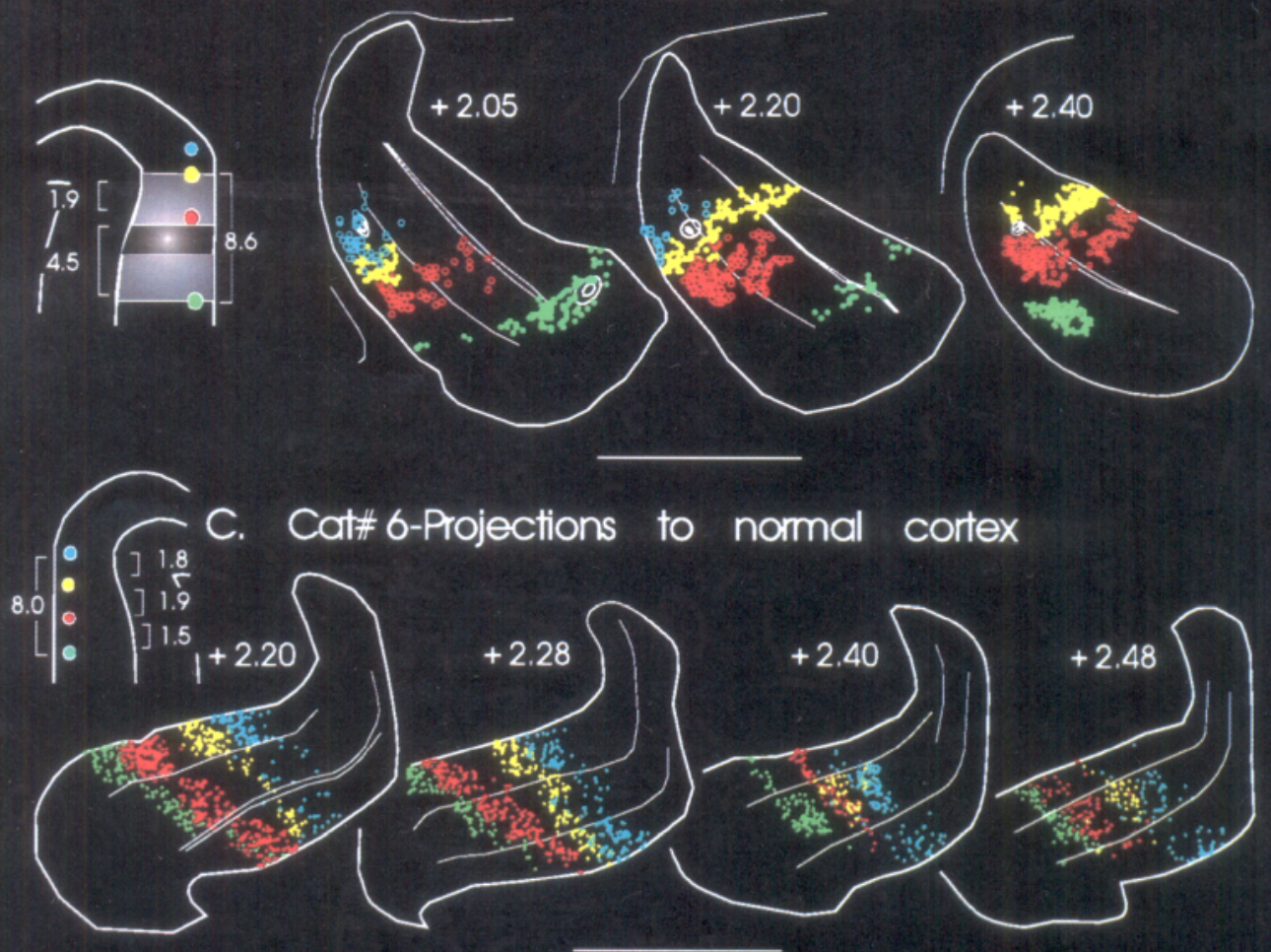

Figure 8. Pattern of labeling in the LGN of cats following cortical injections of 3-4 fluorescent retrograde tracers. A, Labeled populations within the LGN of cat \#5 within four selected parasaggital $50 \mu \mathrm{m}$ sections, with distance between sections indicated in the numbers above each. Insert on the left represents dorsal view of cortex, showing positions of the injection sites, with numbers indicating distances between sites. Distances were measured from the most lateral section through the LGN to the most medial. $B$, Labeled cells within three sections of right LGN of cat \#4 with insert showing injection sites. $C$, Labeling pattern seen in LGN after injections in normal cortex (cat \#6) equivalent to those in $A$ and $B$, with four selected sections shown. In all samples shown, maps were made for every second section, and sections were $50 \mu \mathrm{m}$ thick. The positioning of electrolytic lesions, made at the border between normal and unresponsive LGN during a final recording session, can be seen in $A$ and $B$ (marked in white). Color code of dots: yellow, DY; red, red beads; green, green beads; blue, fast blue. Scale marker $=2.5 \mathrm{~mm}$. 

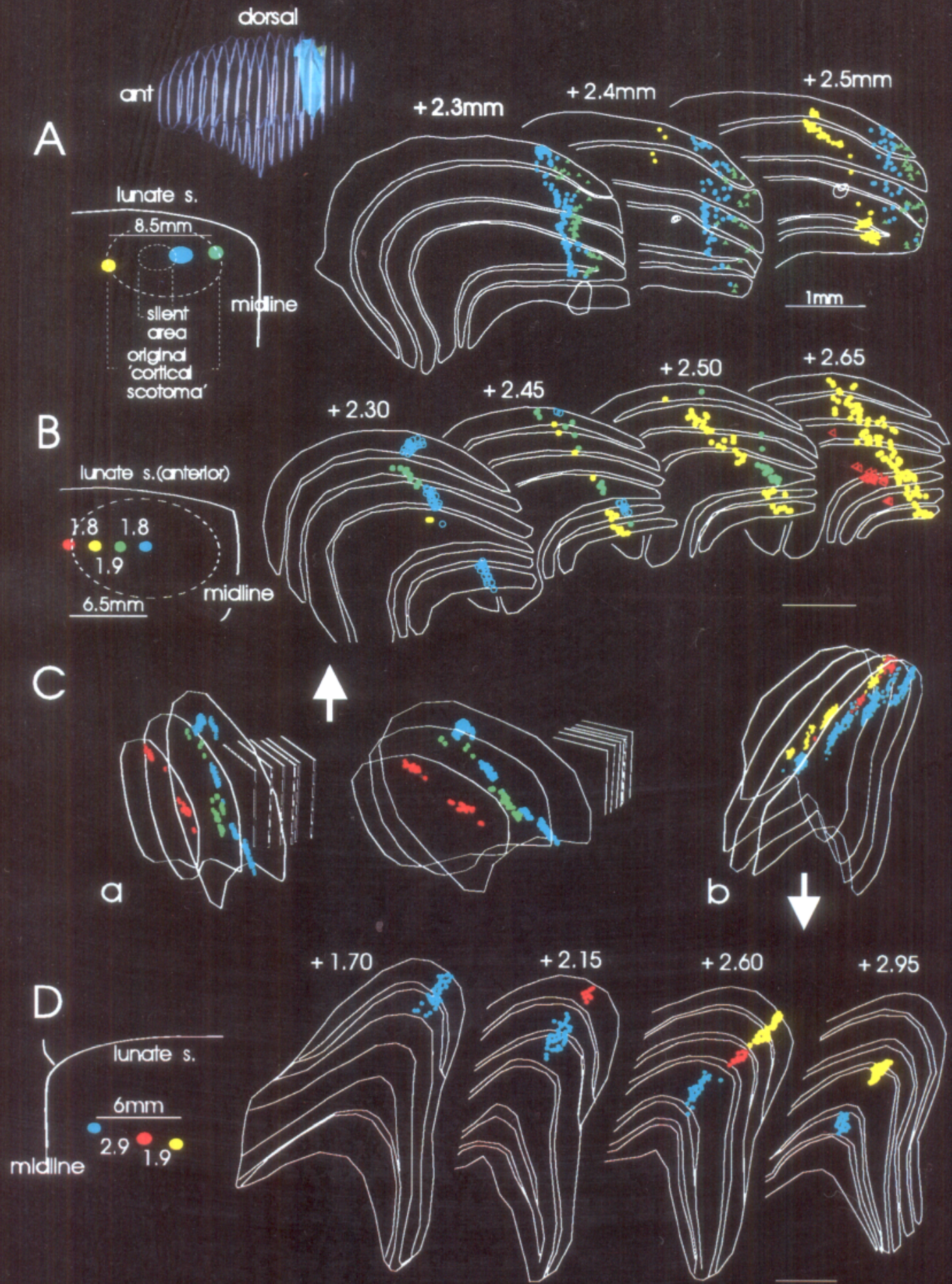

Figure 9. Pattern of labeling within three series of coronal sections in the LGN of monkeys following cortical injections of fluorescent retrograde tracers. A, Labeled populations within the left LGN of monkey \#2. Inset at left shows injection sites within the cortex, relative to the area of the original cortical scotoma and silent area remaining after reorganization. Inset at the top shows a wireframe 3-D reconstruction of the entire LGN, with the zone of labeled cells indicated by a blue and green region, located at the posteromedial portion of the LGN. The labeled region approximates the actual size of the silenced portion of LGN. Numbers above the sections indicate distances along the anteroposterior axis, with 0 mm being the most anterior pole of the LGN. B. Labeled cells within LGN of monkey \#3, with inset at left showing cortical injection sites relative to boundaries of the cortical scotoma. $\mathrm{Ca}$, Three-dimensional reconstructions of columns of labeled cells within the LGN of the lesioned animal shown in series in $B$ (left) and $C b$, for the normal animal shown in series in $D$ (right). D, Labeling pattern seen in LGN of the normal unlesioned monkey \#4 after cortical injections were made in sites similar to those in $A$ and $B$. Sections $50 \mu \mathrm{m}$ thick. Scale marker $=1 \mathrm{~mm}$. Electrolytic lesions are marked in white in $A$. 
A cat \#5 +2.40

Figure 10. Histology showing electrolytic lesions within cat \#5 and monkey \#2. Electrolytic lesions were made during the final recording sessions and enabled us to delineate the boundary between normal and visually unresponsive regions in the histology. Arrows indicate positions of lesions.

\section{B monkey\#2 +2.50}
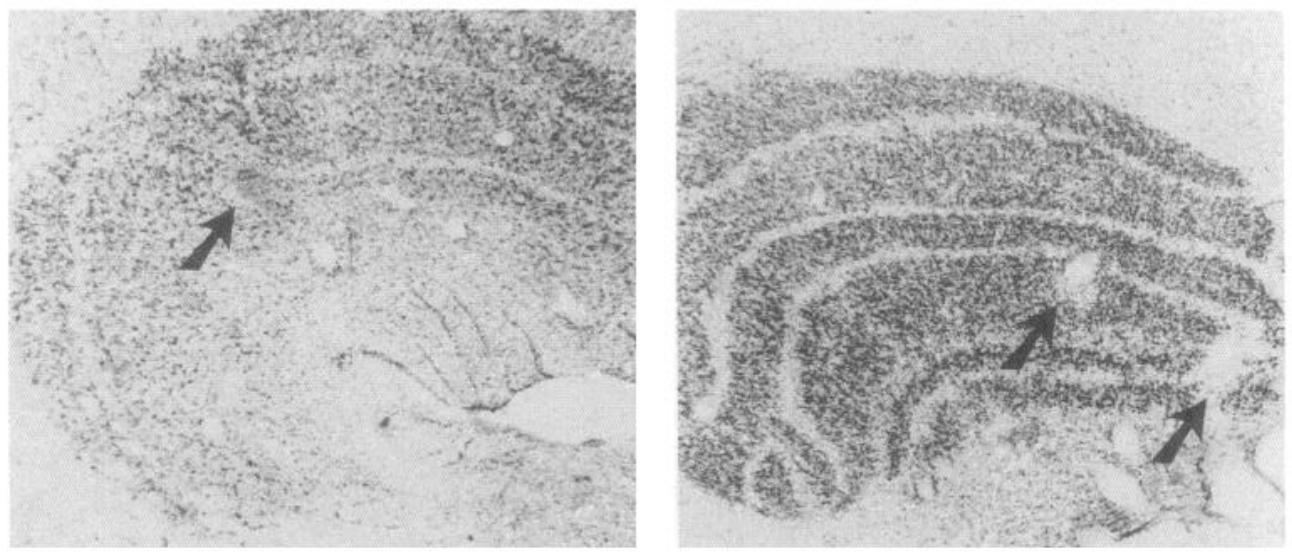

1988, 1991; Turnbull and Rasmusson, 1990; Chino et al., 1992; Pettet and Gilbert, 1992; Sanes et al., 1992), where the expansion of RFs suggests an unmasking of subthreshold afferent inputs (in addition to intrinsic connections) normally held in check by local inhibitory pathways. Since the physical range over which thalamic afferents can exert an influence is not observed to increase after the initial 2 month period (at least within the population examined), these arbors cannot directly affect more than an outlying $1-1.5 \mathrm{~mm}$ of the $3-5 \mathrm{~mm}$ of cortical reorganization observed inside the boundary. In addition, while we cannot dismiss the possibility that small changes of $\sim 100-200$ $\mu \mathrm{m}$ (Eysel et al., 1981) are occurring along the edges of the silent zone within the LGN of the cat and monkey, the relative contribution of this at the cortical level would be negligible.

In contrast to our observations within the visual pathway, there is a growing body of evidence which suggests that within the somatosensory system, subcortical changes may contribute more substantially to reorganization of the body map. Cutting peripheral nerves is known to alter topography within the dorsal horn of the spinal cord (Devor and Wall, 1978, 1981) and afferent terminals have been reported to sprout within the cord following peripheral nerve crush and dorsal root rhizotomy (McMahon and Kett-White, 1991; Cameron et al., 1992; Florence et al., 1993; LaMotte and Kapadia, 1993). Recent work in the squirrel monkey (Garraghty and Kaas, 1991), in which the median and ulnar nerves were ligated, reported substantial reorganization of the somatotopic hand map within the VPL nucleus, and in the rat selective lesions of the trigeminal complex (Rhoades et al., 1987) and dorsal column nuclei (Wells and Tripp, 1987) demonstrated a reorganizational capacity within somatosensory nuclei of the thalamus.

Are there fundamental differences between the visual and somatosensory pathways which could account for the apparent disparity in the reported loci at which functional changes occur? It is certainly true that there are more synaptic steps along the somatosensory pathway at which modifications may take place. Unlike the retinal lesion model (which is not part of the peripheral nervous system), nerve damage or digit amputation (Wall and Cusick, 1984) can result in extensive reorganization of the somatotopic maps within the spinal cord, and afferent terminals synapsing within the cord retain some capacity for outgrowth (see Snow and Wilson, 1991, for review). Primary somatosensory cortex receives tactile information from both crossed (spi- nothalamic) and uncrossed (dorsal column) pathways within the spinal cord so that selective injury to the former may be compensated for by a cruder tactile input from the latter projection. While recent evidence exists for afferent terminal sprouting within the spinal cord following peripheral lesions, there is little evidence for this in second order fibers within the cord or neurons within brainstem nuclei (Rasmusson, 1988; LaMotte et al., 1989; Cameron et al., 1992; Florence et al., 1993; Snow and Wilson, 1991 for review). However, preliminary findings do suggest that dramatic changes in the efficacy of preexisting corticospinal fibers within the cord following partial laminectomy can lead to remarkable recovery of limb function (Galea and I. Darian-Smith, unpublished). The topologic and spatially overlapping organization of the somatosensory and motor thalamus (particularly in the monkey) also provides an ideal forum for circuitry modification (Darian-Smith et al., 1990b; also see Kaas, 1991). Small alterations at each synaptic level will magnify by the time information is distributed from the thalamus to the cortex. By comparison, in the visual pathway perilesion retina does not reorganize, and information is transported directly from a spatially smaller receptor sheet at the retina to the LGN and primary cortex. It seems plausible then that reorganization and functional compensation may occur along a sensory pathway wherever widespread, converging, and spatially overlapping projections exist. Since there is no peripheral remodeling or structure analogous to the spinal cord and brainstem nuclei within the visual pathway, fewer opportunities are available prior to the cortical level, and it may be this distinction which allows us to observe reorganization within the somatosensory thalamus where it is not observed within the LGN. Nevertheless, our results in the visual system would support the contention that some of the reorganization seen in the somatosensory cortex may at least in part be due to changes intrinsic to the cortex.

Two mechanisms have been proposed to account for cortical changes occurring over a period of weeks and months. The first possibility simply involves a change in the efficacy of preexisting synaptic connections as might be facilitated in a use-dependent fashion (Hirsch and Gilbert, 1993). The second involves the sprouting and establishment of new connections, and could encompass synaptogenesis along preexisting fibers, or the physical extension of axonal/dendritic terminals in addition to synaptogenesis (Wells and Tripp, 1987; Keller et al., 1990, 1992; Steward, 1991, for review; Darian-Smith and Gilbert, 1994). In 
addition, alterations to connections would necessarily be accompanied by changes in chemical properties of neurons (Hendry and Carder, 1992; Hendry and Bhandari, 1992). Our observations do not discount the possibility that more than one mechanism may be operating in response to localized loss of sensory input - a combination of changes in preexisting connections and the establishment of new contacts is entirely feasible in a complex system-but they do define a precxisting anatomical substrate through which information may be passed from surrounding normal cortex sufficiently far into the deprived zone. Because of this substrate, our findings imply physical limits for the extent of reorganization possible within the cortex, with the bounds being set according to the lateral extent of the anatomical framework available. In the case of the visual system examined here, that framework appears to be set by the intrinsic horizontal plexus of axonal fibers (Darian-Smith and Gilbert, 1994). Hence we and other investigators (Kaas et al., 1990; Heinen and Skavenski, 1991) have also observed a persistent region of inactivity situated centrally to the visually deprived cortical zone.

Cortical reorganization suggests that the silent region of the LGN receives visually responsive input from the cortex, though we have no evidence for this. This raises two interesting questions: specifically, what is the functional role of the corticogeniculate pathway, and, more generally, what is the connectional status of efferent neurons leaving the reorganized cortical zone? It remains puzzling that the LGN, with nonoriented monocular cells, receives a powerful projection from the cortex consisting of oriented binocular inputs. The orientation information could be lost by convergence but the loss of binocular information suggests that feedback is modulatory under normal circumstances and, even when reorganized, would not produce a measurable change in the absence of active input from the retina. We presently have no information about the functional status of synaptic contacts distant to the cortical scotoma, though one might speculate that reorganization occurs within matching visuotopic locations (area 18), within a similar time frame, and with the recruitment of similar mechanisms.

Intuitively, we must assume that the mammalian central nervous system has evolved in a way which allows it to adapt optimally to a range of environmental circumstances. The functional significance of the type of topographic reorganization observed in the present study remains unclear, and will vary according to the time course of the changes. The cortical reorganization described following bilateral retinal lesions will not restore sight to the damaged retina but it may alter our perception of the impaired image by allowing a perceived fill-in of contours and surfaces crossing the scotoma in a way that is less visually distracting to the animal. Patients with focal uni-/or bilateral scotomas frequently describe a perceptual filling-in of the blind spot induced by the retinal injury (Craik, 1966; Ramachandran and Gregory, 1991). Our results concerning the source of reorganization following retinal lesions may not be restricted to central nervous system lesions, but may instead suggest that similar cortical mechanisms play a role in normal experiencedependent adaptational mechanisms in primary sensory cortex.

The work described here provides insight into the loci at which cortical reorganization occurs, as it is observed weeks after retinal lesions remove sensory input from a focal region of cortex. In the visual pathway, substantial cortical reorganization is not mediated by the thalamus or through the normal spread or extension of thalamocortical arbors. Instead, and given our results, the most likely candidate for the extensive $6-10 \mathrm{~mm}$ of reorganization observed is a preexisting framework of intracortical connections.

\section{References}

Allard T, Clark SA, Jenkins WM, Merzenich MM (1991) Reorganization of somatosensory area $3 \mathrm{~b}$ representations in adult owl monkeys after digital syndactyly. J Neurophysiol 66:1048-1058.

Blasdel GG, Lund JS (1983) Termination of afferent axons in macaque striate cortex. J Ncurosei 3:1389-1413.

Calford MB, Tweedale R (1988) Immediate and chronic changes in responses of somatosensory cortex in adult flying-fox after digit amputation. Nature 332:446-448.

Calford MB, Tweedale R (1991) Acute changes in cutaneous receptive fields in primary somatosensory cortex after digit denervation in adult flying fox. J Neurophysiol 65:178-187.

Cameron AA, Pover CM, Willis WD, Coggeshall RE (1992) Evidence that fine primary afferent axons innervate a wider territory in the superficial dorsal horn following peripheral axotomy. Brain Res 575:151-154.

Chino YM, Smith III EL, Wada H, Ridder III WL, Langston AL Lesher GA (1991) Disruption of binocularly correlated input leads to deficits in spatial properties of striate cortical neurons in cats. $\mathbf{J}$ Neurophysiol 65:841-859.

Chino YM, Kaas JH, Smith III EL, Langston AL, Cheng H (1992) Rapid reorganization of cortical maps in adult cats following restricted deafferentation in retina. Vision Res 32:789-796.

Craik KJW (1966) On the effects of looking at the sun. In: The nature of psychology (Sherwood SL, ed). Cambridge: Cambridge UP.

Darian-Smith C, Darian-Smith I (1993) Thalamic projections to areas $3 \mathrm{a}, 3 \mathrm{~b}$, and 4 in the sensorimotor cortex of the mature and infant macaque monkey. J Comp Neurol 335:173-199.

Darian-Smith C, Gilbert CD (1994) Axonal sprouting accompanies functional reorganization in adult cat striate cortex. Nature 368: $737-740$

Darian-Smith C, Darian-Smith I, Cheema SS (1990a) Thalamic projections to sensorimotor cortex in the macaque monkey: use of multiple retrograde fluorescent tracers. J Comp Neurol 299:17 46.

Darian-Smith C, Darian-Smith I, Cheema SS (1990b) Thalamic projections to sensorimotor cortex in the newborn macaque. J Comp Neurol 299:47-63.

Devor M, Wall PD (1978) Reorganization of spinal cord sensory map after peripheral nerve injury. Nature 276:75-76.

Devor M, Wall PD (1981) Effect of peripheral nerve injury on receptive fields of cells in the cat spinal cord. J Comp Neurol 199: 277-291.

Donoghue JP, Suner S, Sanes JN (1990) Dynamic organization of primary motor cortex output to target muscles in adult rats. II. Rapid reorganization following motor nerve lesions. Exp Brain Res 79: 492-503.

Eysel UT, Gonzalez-Aguilar F, Mayer U (1980) A functional sign of reorganization in the visual system of adult cats: lateral geniculate neurons with displaced receptive fields after lesions of the nasal retina. Brain Res 181:285-300.

Eysel UT, Gonzalez-Aguilar F, Mayer U (1981) Late spreading of excitation in the lateral geniculate nucleus following visual deafferentation is independent of the size of retinal lesions. Brain Res 204:189-193.

Ferster D, LeVay S (1978) The axonal arborizations of lateral geniculate neurons in the striate cortex of the cat. J Comp Neurol 182: 923-944.

Florence SL, Garraghty PE, Carlson M, Kaas JH (1993) Sprouting of peripheral nerve axons in the spinal cord of monkeys. Brain Res 601:343-348.

Freund TF, Martin KAC, Whitteridge D (1985) Innervation of cat visual areas 17 and 18 by physiologically identified $x$ - and y-type thalamic afferents. I. Arborization patterns and quantitative distribution of postsynaptic elements. J Comp Neurol 242:263-274.

Freund TF, Martin KAC, Soltesz I, Somogyi P, Whitteridge D (1989) Arborisation pattern and postsynaptic targets of physiologically identified thalamocortical afferents in striate cortex of the macaue monkey. J Comp Neurol 289:315-336.

Garraghty PE, Kaas JH (1991) Functional reorganization in adult monkey thalamus after peripheral nerve injury. NeuroReport $2: 747-$ 750.

Gilbert CD, Wiesel TN (1979) Morphology and intracortical projec- 
tions of functionally identified neurons in cat visual cortex. Nature 280: $120-125$.

Gilbert CD, Wiesel TN (1983) Clustered intrinsic connections in cat visual cortex. J Neurosci 3:1116-1133.

Gilbert CD, Wiesel TN (1989) Columnar specificity of intrinsic horizontal and corticocortical connections in cat visual cortex. J Neurosci 9:2432-2442.

Gilbert CD, Wiesel TN (1992) Receptive field dynamics in adult primary visual cortex. Nature 356:150-152.

Gilbert CD, Hirsch JA, Wiesel TN (1990) Lateral interactions in visual cortex. Cold Spring Harbor Symp Quant Biol 55:663-677.

Heinen SJ, Skavenski AA (1991) Recovery of visual responses in foveal V1 neurons following bilateral foveal lesions in adult monkey. Exp Brain Res 83:670-674.

Hendry S, Bhandari MA (1992) Neuronal organization and plasticity in adult monkey visual cortex: immunoreactivity for microtubuleassociated protein 2. Vis Neurosci 9:445-459.

Hendry S, Carder RK (1992) Organization and plasticity of GABA neurons and receptors in monkey visual cortex. In: Progress in Brain Research, Vol 90 (Mize RR, Marc RE, Sillito AM, eds), pp 477-502. New York: Elsevier.

Hirsch J, Gilbert CD (1993) Long-term changes in synaptic strength along specific intrinsic pathways in the cat's visual cortex. J Physiol (Lond) $461: 24 \%-262$.

Hubel DH, Wiesel TN (1962) Receptive fields, binocular interaction and functional architecture in the cat's visual cortex. J Physiol (Lond) 160:106-154.

Hubel DH, Wiesel TN (1974) Uniformity of monkey striate cortex: a parallel relationship between field size, scatter and magnification factor. J Comp Neurol 158:295-306.

Humphrey AL, Sur M, Uhlrich DJ, Sherman SM (1985) Projection patterns of individual $\mathrm{X}$ and $\mathrm{Y}$ cell axons from the lateral geniculate nucleus to cortical area 17 in the cat. J Comp Neurol 233:159-189.

Kaas JH (1991) Plasticity of sensory and motor maps in adult mammals. Annu Rev Neurosci 14:137-167.

Kaas JH, Krubitzer LA, Chino YM, Langston AL, Polley EH, Blair $N$ (1990) Reorganization of retinotopic cortical maps in adult mammals after lesions of the retina. Science 248:229-231.

Keizer K, Kuypers HGJM, Huisman AM, Dann O (1983) Diamidino yellow dihydrochloride (DY.2HCl): a new fluorescent retrograde neuronal tracer, which migrates only very slowly out of the cell. Exp Brain Res 51:179-191.

Kelahan AM, Doetsch GS (1984) Time-dependent changes in the functional organization of somatosensory cerebral cortex following digit amputation in adult raccoons. Somatosens Res 2:49-81.

Keller A, Arissian K, Asanuma H (1990) Formation of new synapses in the cat motor cortex following lesions of the deep cerebellar nuclei. Exp Brain Res 80:23-33.

Keller A, Arissian K, Asanuma H (1992) Synaptic proliferation in the motor cortex of adult cats after long-term thalamic stimulation. J Neurophysiol 68:295-308.

LaMotte CC, Kapadia SE (1993) Deafferentation-induced terminal field expansion of myelinated saphenous afferents in the adult rat dorsal horn and the nucleus gracilis following pronase injection of the sciatic nerve. J Comp Neurol 330:83-94.

LaMotte CC, Kapadia SE, Kocol CM (1989) Deafferentation-induced expansion of saphenous terminal field labelling in the adult rat dorsal horn following pronase injection of the sciatic nerve. J Comp Neurol 288:311-325.

Malpelli JG, Baker FH (1975) The representation of the visual field in the lateral geniculate nucleus of Macaca mulatta. J Comp Neurol 161:569-594.

Martin KAC, Whitteridge D (1984) Form, function and intracortical projections of spiny neurnes in the striate visual cortex of the cat. J Physiol (Lond) 353:463-504.

Mason CA, Robson JA (1979) Morphology of retino-geniculate axons in the cat. Neuroscience 4:79-97.

McMahon SB, Kett-White R (1991) Sprouting of peripherally regenerating primary sensory neurones in the adult central nervous system. J Comp Neurol 304:307-315.

Merzenich MM, Kaas JH, Wall JT, Nelson RJ, Sur M, Felleman D (1983a) Topographic reorganization of somatosensory cortical areas $3 b$ and 1 in adult monkeys following restricted deafferentation. Neuroscience 8:33-55.

Merzenich MM, Kaas JH, Wall JT, Sur M, Nelson RJ, Felleman D (1983b) Progression of change following median nerve section in the cortical representation of the hand in areas $3 \mathrm{~b}$ and 1 in adult owl and squirrel monkeys. Neuroscience 10:639-665.

Merzenich MM, Nelson R.I, Stryker MP, Cynader MS, Schoppmann A, Zook JM (1984) Somatosensory cortical map changes following digital amputation in adult monkeys. J Comp Neurol 224:591-605.

Pettet MW, Gilbert CD (1992) Dynamic changes in receptive field size in cat primary visual cortex. Proc Natl Acad Sci USA 89:83668370 .

Pons T, Garraghty PE, Ommaya AK, Kaas JH, Taub E, Mishkin M (1991) Massive cortical reorganization after sensory deafferentation in adult macaques. Science 252:1857-1860.

Rajan R, Irvine DRF, Wise LZ, Heil P (1993) Effect of unilateral partial cochlear lesions in adult cats on the representation of lesioned and unlesioned cochleas in primary auditory cortex. J Comp Neurol 338:17-49.

Ramachandran VS, Gregory TL (1991) Perceptual filling in of artificially induced scotomas in human vision. Nature 350:699-702.

Ramachandran VS, Rogers-Ramachandran D, Stewart M (1992) Perceptual correlates of massive cortical reorganization. Science 258: $1159-1160$.

Rasmusson DD (i982) Reorganization of raccoon somatosensory cortex following removal of the fifth digit. J Comp Neurol 205: 313-326.

Rasmusson DD (1988) Projections of digit afferents to the cuneate nucleus in the raccoon before and after partial deafferentation. $J$ Comp Neurol 277:549-556.

Rasmusson DD, Nance DM (1986) Non-overlapping thalamocortical projections for separate forepaw digits hefore and after cortical reorganization in the raccoon. Brain Res Bull 16:399-406.

Rasmusson DD, Turnbull BG, Leech CK (1985) Unexpected reorganization of somatosensory cortex in a raccoon with extensive forelimb loss. Neurosci Lett 55:167-172.

Rhoades RW, Belford GR, Killackey HP (1987) Receptive-field properties of rat ventral posterior medial neurons before and after selective kainic acid lesions of the trigeminal brain stem complex. J Neurophysiol 57:1577-1600.

Robertson D, Irvine D (1989) Plasticity of frequency organization in auditory cortex of guinea pigs with partial unilateral deafness. J Comp Neurol 282:456-471.

Rockland KS, Lund JS (1982) Widespread periodic intrinsic connections in the tree shew visual cortex. Brain Res 169:19-40.

Rockland KS, Lund JS (1983) Intrinsic laminar lattice connections in primate visual cortex. J Comp Neurol 216:303-318.

Rockland KS, Virga A (1989) Terminal arbors of individual "feedback" axons projecting from area V2 to V1 in the Macaque monkey: a study using immunohistochemistry of anterogradely transported Phaseolus vulgaris-leucoagglutinin. J Comp Neurol 285:5472 .

Rockland KS, Saleem KS, Tanaka K (1994) Divergent feedback connections from areas V4 and TEO in the macaque. Vis Neurosci, in press.

Sanderson KJ (1971) The projection of the visual field to the lateral geniculate and medial interlaminar nuclei in the cat I Comp Neurol 143:101-117

Sanes JN, Suner S, Lando JF, Donoghue JP (1988) Rapid reorganization of adult rat motor cortex somatic representation patterns after motor nerve injury. Proc Natl Acad Sci USA 85:2003-2007.

Sanes JN, Suner S, Donoghue JP (1990) Dynamic organization of primary motor cortex output to target muscles in adult rats. I. Longterm patterns of reorganization following motor or mixed peripheral nerve lesions. Exp Brain Res 79:479-491.

Sanes JN, Wang J, Donoghue JP (1992) Immediate and delayed changes of rat motor cortical output representation with new forelimb configurations. Cereb Cortex 2:141-152.

Schmid LM, Rosa MGP, Calford MB (1993) Reorganizational plasticity in the primary visual cortex (IV) of adult cats occurs following monocular retinal lesions. Soc Neurosei Abstr 19:1801.

Snow PJ, Wilson P (1991) Plasticity in the somatosensory system of developing and mature mammals - the effects of injury to the central and peripheral nervous system. In: Progress in sensory physiology, Vol 11 (Ottoson D, ed), pp 1-482. Berlin: Springer.

Steward O (1991) Synapse replacement on cortical neurons following denervation. In: Cerebral cortex, Vol 9 (Peters A, Jones EG, eds), pp 81-131. New York: Plenum. 
Turnbull BG, Rasmusson DD (1990) Acute effects of total or partial denervation on raccoon somatosensory cortex. Somatosens Mot Res $7: 365-389$.

Turnbull BG, Rasmusson DD (1991) Chronic effects of total or partial digit denervation on raccoon somatosensory cortex. Somatosens Mot Res 8:201-213.

Tusa RJ, Palmer LA, Rosenquist AC (1978) The retinotopic organi- zation of area 17 (striate cortex) in the cat. J Comp Neurol 177: 213-236.

Wall JT, Cusick CG (1984) Cutaneous responsiveness in primary somatosensory (S-I) hindpaw cortex before and after partial hindpaw deafferentation in adult rats. J Neurosei 6:1499-1515.

Wells J, Tripp LN (1987) Time course of reactive synaptogenesis in the subcortical somatosensory system. J Comp Ncurol 255:466-475. 